\title{
A Review of Literature for the Structural Assessment of Mitred Bends
}

\author{
J. Wood ${ }^{\mathrm{a}}$ \\ ${ }^{a}$ Department of Mechanical Engineering, University of Strathclyde, 75 Montrose Street, \\ Glasgow G1 1XJ, UK
}

\begin{abstract}
This paper presents a state-of-the-art review of literature available for the structural assessment of all types of mitred pipe bends. Compared with smooth bends, the volume of literature available for mitres is less extensive and its scope is not as wide. Historically, this reflects a reduced application level, as well as a less demanding range of applications, such as non-high temperature use. There is also the issue that an analysis of a mitred bend is complicated by discontinuity stresses, as well as those due to cross-section ovalisation. This fact, delayed the development of non-linear analysis of mitred bends. Nevertheless, there is now a substantial body of work on mitred bends. This review tabulates and characterises all publications to date in chronological order. The details of experimental specimens are highlighted, with a view to these perhaps providing useful verification data for any future finite element analysis for example. Issues of particular interest to pipework designers are discussed, including the effects of combinations of loading, out-of-circularity, tangent pipe length and flanges. Failure characteristics and loads are discussed where relevant. Topics for further research are also noted. For example, comprehensive design curves do not exist for the elastic and plastic behaviour of all mitre types, over a practical range of geometry and loading parameters. Similarly, there is still scope for further work on the effect of combined loading, end effects and out-of-circularity. Limit, collapse and burst loads are not yet available across the entire spectrum of bends and loading parameters either. Creep and optimisation represents virgin territory as far as mitred bends are concerned and given that unforeseen vibration is a common source of high-cycle fatigue failure in pipework, there must also be scope for vibration induced fatigue studies.
\end{abstract}

Keywords: Mitred pipe bend; literature review, structural assessment.

\section{Introduction}

Mitred bends are widely used in industry. In particular, applications include large diameter pipework or ducting in chemical complexes, desalination plants, water supply and nuclear power stations, where the manufacture of smooth bends may be either impractical or uneconomical. In many cases designers will prefer to utilise smooth pipe bends due to the lack of discontinuity, the relatively smaller stress concentration and the more favourable flow characteristics. However, in large diameter applications or applications with restricted space or a tight budget, mitred bends still find application.

A detailed review and assessment of every document published on mitred bends is obviously not possible within the scope of this paper. The main aim of this review therefore is to draw attention to the information available in the open literature, to give the reader an indication of scope, to highlight specific topics of interest to the designer and to identify 
possible areas for further research. The challenge being to try and summarise this research in a useful manner to industry and academia today.

While such a chronological presentation of references [1-101] in tables 1-3, is no doubt interesting from a historical viewpoint, it is perhaps true to say, that most of the early theoretical work, in particular, will hold little real interest. Much of the early theoretical work, which was clearly ground-breaking at the time, related to the development and subsequent refinement of fundamental theoretical details. This activity was often informed by comparisons with experiments. For example, early theories assumed the un-reinforced segment of a multimitre to have a uniform flattening and the intersection of a reinforced mitre to be rigidly constrained. Later theories relaxed these constraints and involved series expansions to allow for the decay of cross-sectional ovalisation, postulating the existence of long and short decay lengths. This not only improved comparison with experiment, but also allowed consideration of the effects of end constraints. It is also apparent from the early documents that the development of the theory and general topics of interest had much in common with smooth pipe bends. This is not surprising given that the basic behaviour of these components is similar. This includes the fact that both develop an increase in flexibility and local stress levels due to cross-section ovalisation. The mitre obviously has the added complexity of discontinuity stresses at the intersection. In the early theoretical work, an edge solution was developed for this case, which was then superimposed on the flattening analysis.

The later papers invariably contain the refined theories and provide best comparisons with experiment in general. However, today the real relevance to industry of even these later theories, must be questionable. Interestingly, as far back as 1970, Sobiesczanski[22] felt that the Finite Element Method was the 'analytical tool' that should be used and that his theoretical concept of an 'equivalent smooth bend' should be abandoned. Today, the Finite Element Method has a dominant role in the study of engineering structures and components in general and most organisations faced with the need to examine a mitred pipe bend will almost certainly use this as the preferred approach. In the general area of 'Design by Analysis' of pressure vessels and components, finite element analysis is now generally preferred to hand calculations using shell theory. The mitred bend also represents a very challenging theoretical problem and this is why it has kept numerous researchers busy for decades. The number of engineers in general, who can understand such theories and apply them, is almost certainly in decline. Even Kitching, who had spent many years developing and refining his theoretical solutions, turned to finite element analysis with his research students, when examining non-linear behaviour. It should be recognised however that these theoretical developments also had an influence on code guidelines and rules over the years and their contribution to understanding of the subject and industrial practice should not be underestimated. Even though today, finite element analysis is the preferred approach, there is no doubt that having a knowledge of the various relevant issues in the behaviour of such components will be invaluable. Many of these issues were identified in the development of the theory and it is these issues that will provide a focus for this review of literature.

Unlike the theoretical development, the extensive (and no doubt expensive) experimental testing carried out over the years is generally still highly relevant today. The issue of validation of finite element models is perhaps surprisingly still as important today as it ever was. It is widely recognised that benchmarking finite element results against quality experimental data is a valuable exercise - both in terms of the education of the analyst and also in terms of validating the model. A study of the significance of real-world variables relating to geometry, material and boundary conditions, can be an enlightening experience for analysts. As finite element analysis moves into more complex combined physical phenomena (e.g. fluidflexible structure interaction), where no theoretical benchmark is available, the importance of experimental validation increases. 


\section{Review of Literature on Mitres}

This paper presents an up-to-date and comprehensive list of all references relating to the structural behaviour of mitred pipe bends of all types. The general nature and content of these publications is presented in tables $1-3$. A more extensive review of the literature, up to 1983 , on all aspects of mitred bend behaviour is available in a supplement to reference [35]. This reference discusses the significant conclusions from each publication, which is obviously not possible in the present paper, due to space restrictions.

Before considering any details relating to previous work, it may prove instructive to discuss the general structure of these tables and how they may be used. There are 3 tables - one for single un-reinforced mitred bends, one for single reinforced mitred bends (where the mitre intersection is reinforced in some way to reduce ovalisation and hence stresses) and one for multi-mitre bends (also known as gusseted or lobster-back bends). The 'spectrum' of mitred bends is illustrated in figure 1 .

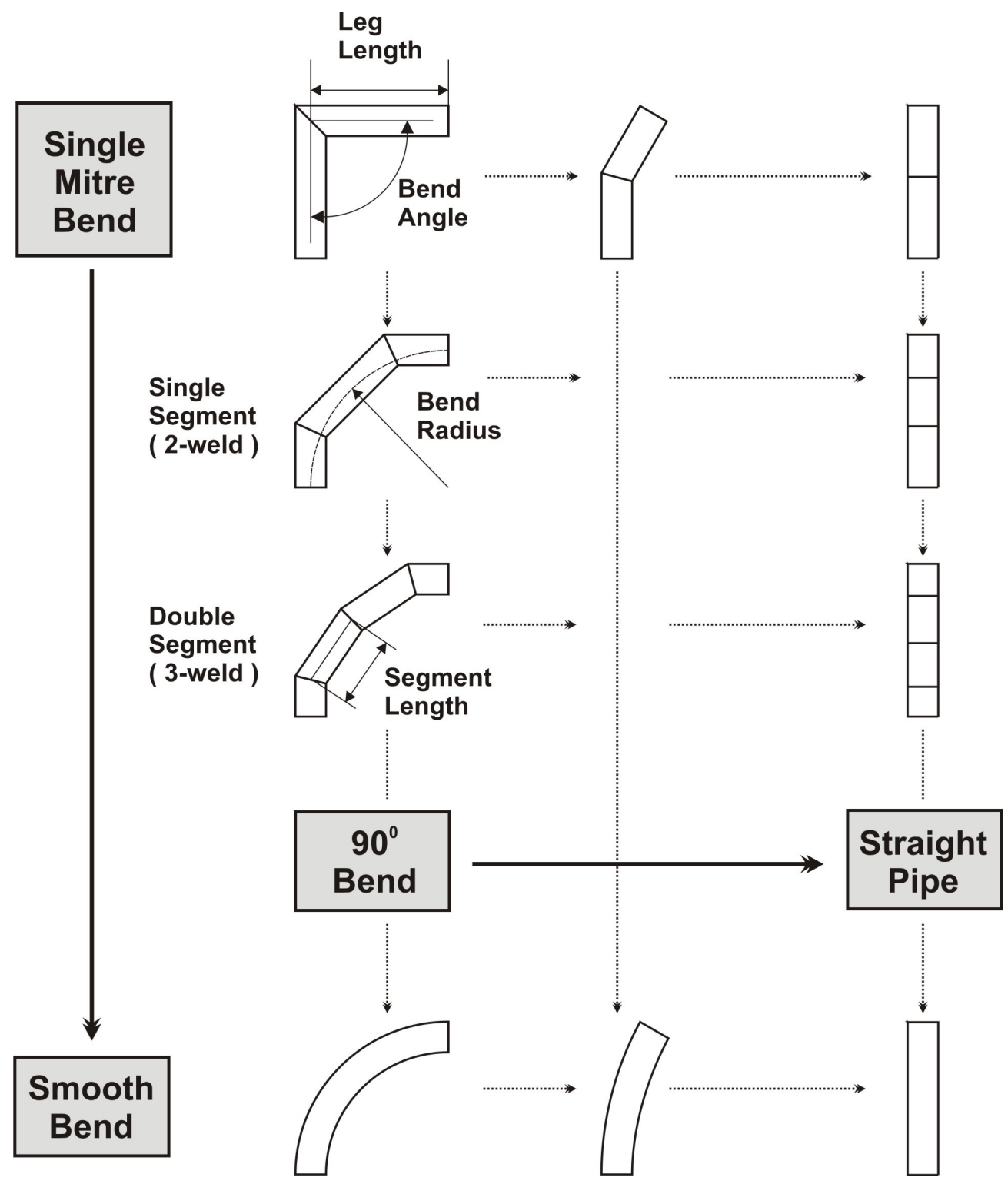

Figure 1. Mitred Pipe Bend 'Spectrum' 
This figure shows the convergence towards a straight-pipe solution as bend angle increases and towards a smooth pipe solution as the number of segments increases. It should be borne in mind however, that any welded intersection will give rise to localised peak stresses, which will in turn be important in relation to fatigue performance.

The various types of reinforced mitre bends are shown in figure 2. The types of mitre reinforcement includes:

(a) Weld metal - even this represents a degree of mitre reinforcement. It will generally be more significant for bends of high $a / t$ ratio (where ' $a$ ' is the mean radius of the pipe and ' $t$ ' is the pipe wall thickness) and will have a role in the determination of fatigue hot-spot stresses. It is also recognised that any mismatch between weld and parent metal will also affect the degree of reinforcement at the intersection.

(b) Local area reinforcement - more common with GRP (glass reinforced plastic) bends. The possibility of determining an optimum thickness profile exists, but this has never been investigated.

(c) Elliptical insert.

(d) Gusset plates.

(e) Reinforcing ring - with various profiles of stiffening section shown in (i) to (vii). The figure shows a variable profile ring, but uniform profile is also used. The possibility of determining an optimum profile also exists, but this has never been investigated.

(f) Represents an assumption commonly made in the analysis of mitred pipe bends, prior to the popularity of finite element analysis. This has been shown not to be representative, even for reinforced mitres.

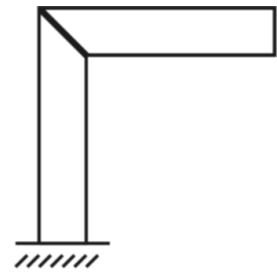

(a)

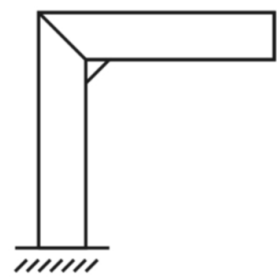

(d)

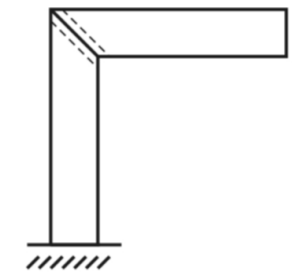

(b)

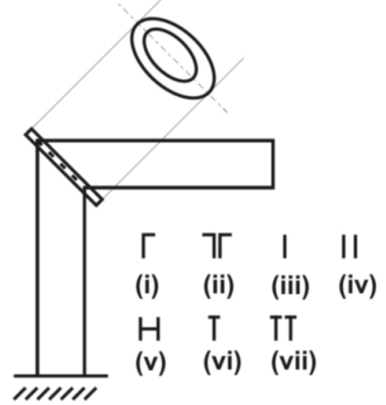

(e)

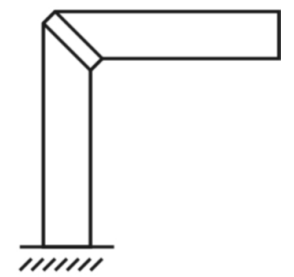

(c)

Figure 2. Types of Reinforcement

Many large diameter mitred pipe bends may also have some form of internal reinforcement due to the cascade blading, which is sometimes attached to the inside surfaces of the elliptical insert (c), to improve flow characteristics. The effect of this is limited in some designs by connecting the blading to the bend at 'neutral' positions and using sliding joint connections. 
As can be seen from figure 2, the variety of reinforcement that can be used to reduce the stress concentration effect and ovalisation of the elliptical intersection is large. Holland[20, 47] emphasized the dangers in assuming a perfectly clamped joint (f) when analysing a reinforced mitre. Owen, Holland \& Emmerson[12], for the case of internal pressure, discussed the problems of selecting the most appropriate size and shape of stiffening ring.

If the segment length of a multi-mitre was large enough to permit the analysis of each intersection as a single mitre, then the information relating to single mitres would be directly applicable.

In the tables, for each type of bend, the references are presented in chronological order. This can in itself provide an interesting picture of activity in this area. For example, the early interest was clearly driven by the design considerations of the Magnox nuclear power station development in the UK. The design of these stations required large diameter ducting, which generally precluded the use of smooth pipe bends. This work was clearly challenging from an academic viewpoint and as a consequence generated research activity in a number of UK Universities. The extensive research activity by Kitching at the University of Manchester, over a long period of time, is noteworthy in this regard.

The new ITER fusion nuclear reactor [92] is likely to utilise mitred bends in the waveguides. These waveguides, which are $72 \mathrm{~m}$ in length, but only $63.5 \mathrm{~mm}$ diameter, include 9 mitred bends. Although the principles of operation of the fusion and early Magnox reactors are completely different, it is interesting to note the similarities in terms of solutions to the challenges brought about by the operating temperatures. Instead of transmitting a fluid containing energy, the evacuated waveguides transmit microwave power. To minimise transmission losses, the thermal distortion of the lines must be minimised and to this end, the transmission lines contain expansion bellows. The mitred bends contain mirrors to reflect the microwave beam and these must also be held 'rigid' during operation. In addition, the bends absorb small amounts of power and will have to be actively cooled. Mitres pipes are also present in pebble-bed reactor designs. Interest in mitred bends for nuclear power generation is not at an end, it would appear.

The early work in the US, laying the foundations for the fatigue strength reduction factor, stress concentration factor and flexibility factor data in today's ASME design codes for such components, is also apparent in tables 1-3. The trend in mitred bend publication is shown in figure 3.

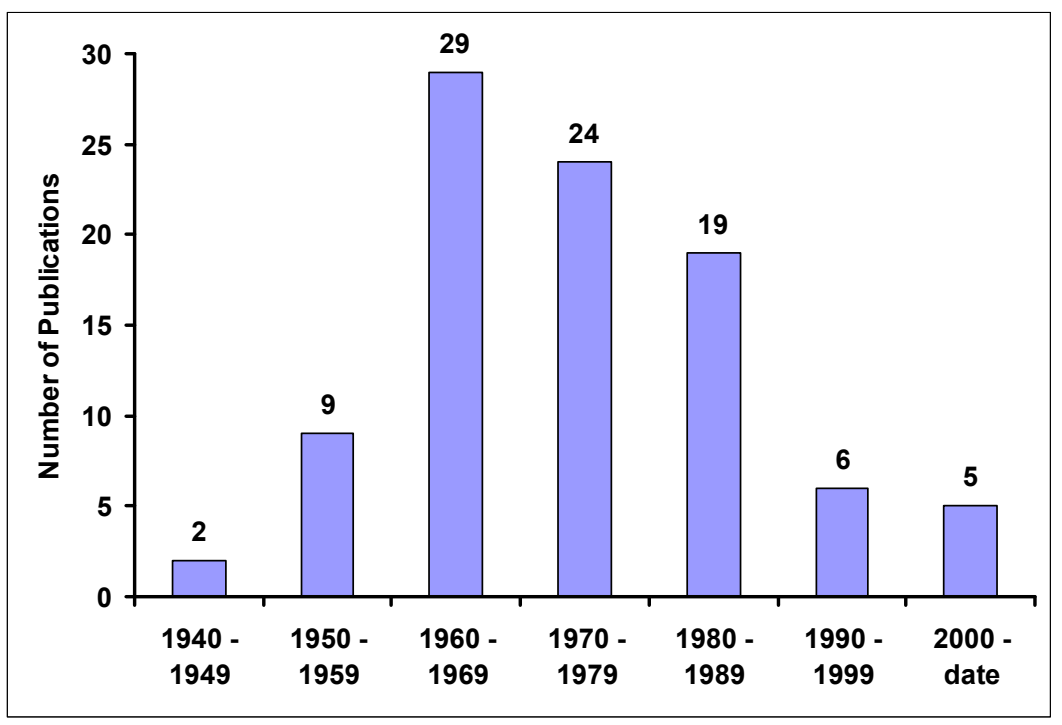

Figure 3. $\quad$ Mitre Pipe Bend Publications 
The data in tables 1-3 distinguishes theoretical and experimental papers, for in-plane bending (IPB), out-of-plane bending (OPB), torsion (TORS) and internal pressure (PRESS). The tables also detail the salient dimensions of the experimental specimens. This would hopefully allow anyone seeking validation for any finite element model to select an experiment with similar characteristics. The loading arrangements, typically used in experiments, are shown in figure 4. From these arrangements, it is clear that in some cases, the loading is not symmetrical about the mitre intersection and as a consequence, each leg of the mitre will have a different stress field. So for example, in many instances, a notional out-of-plane bending load will also subject parts of the bend to torsion and shear (including the mitre intersection).

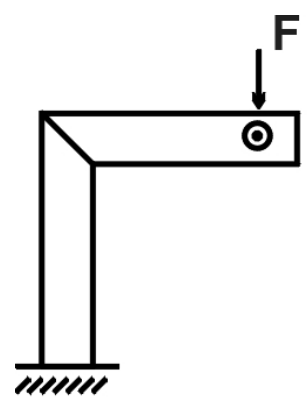

(a)

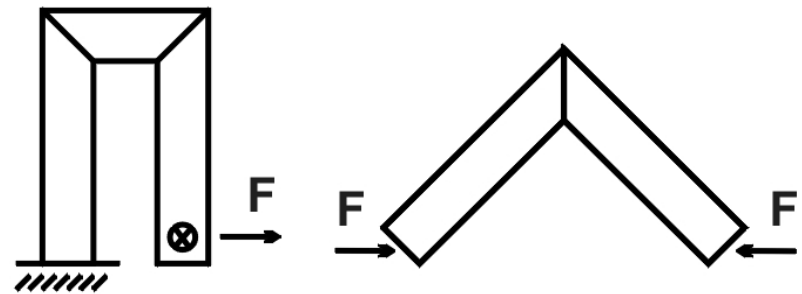

(c)

Figure 4. Typical Experimental Loading Arrangements

Unlike experimental studies, theoretical analyses invariably examined simplified symmetrical cases, with one loading action. Finite element studies, have also been employed to examine various unit loading cases as well as to accurately reflect an experimental test set-up. Various unit loading cases may be examined using the force actions shown in figure 5 . These unit loading cases, may be built up into more complex loading scenarios using the Principle of Superposition of States (where relevant). There are various effects that can invalidate this principle, including plasticity, large displacements and contact. In the case of pipe bends, the presence of pressure loading can also invalidate superposition of results from individual loading cases and this is discussed further in section 3.1. Use of symmetrical and asymmetrical boundary conditions can be used to restrict the model to a quarter of the bend in the illustration shown. With the increasing power of computers, asymmetrical (perhaps even symmetrical) idealisations are less likely to be used, with most analysts simply modelling the entire geometry. 

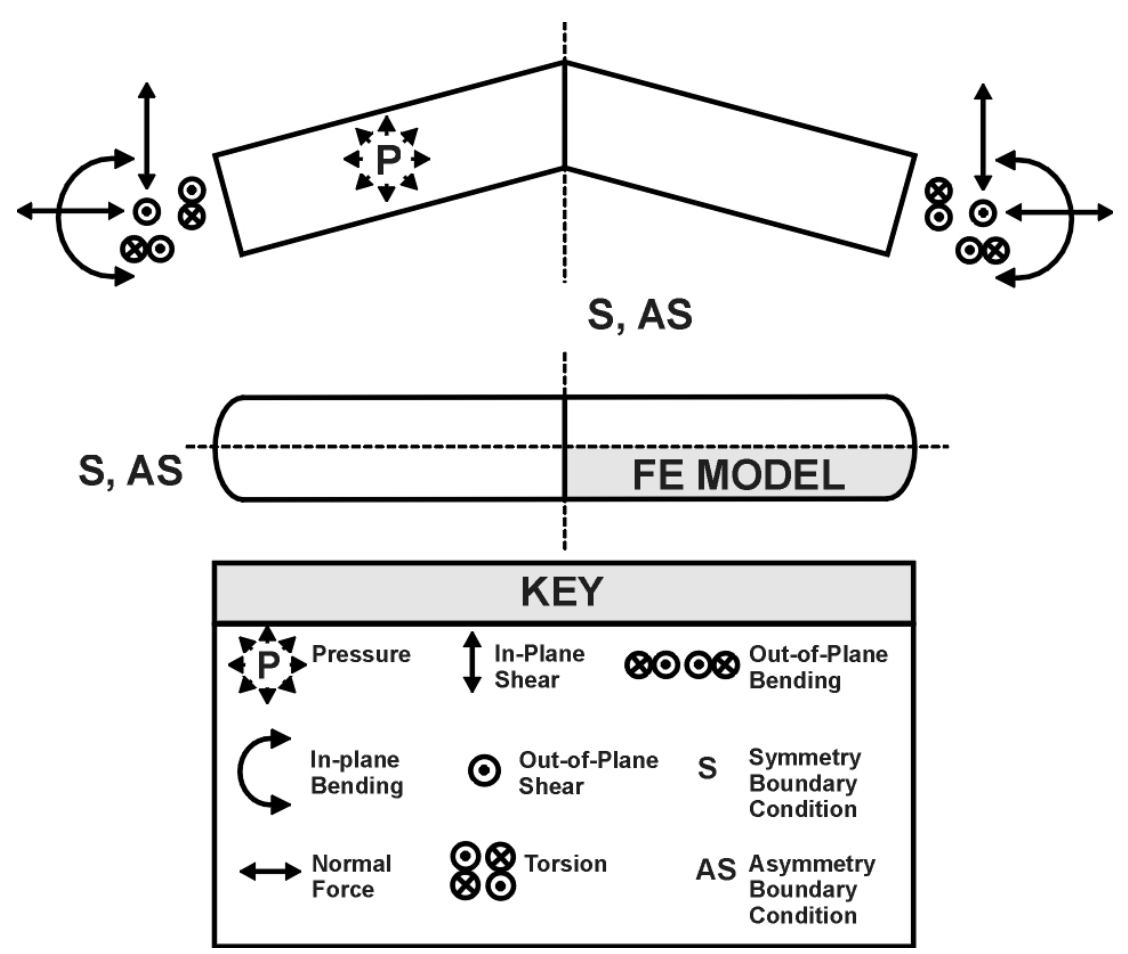

Figure 5. Unit Load Case Possibilities

Tables 1-3 also identify any references where plastic behaviour has been examined (e.g. burst or collapse loads). These papers are often experimental in nature. The tables also highlight any unusual considerations under the column heading 'OTHER'.

\section{Special Interest Topics}

The following topics relate to issues that are of particular interest to engineers and designers concerned with mitred pipe bends. In each section, the information is presented in the same order as the tables - single un-reinforced mitres, followed by single reinforced mitres and then multi-mitres.

\subsection{Combinations of Loads}

With the possible exception of internal pressure, plasticity and contact, the combined effect of various loadings on the elastic response of mitred pipe bends can often be obtained using the 'Principle of Superposition', which is known to be valid as long as behaviour is linear, the deformations are small and these small displacements do not affect substantially the action of the external forces. When internal pressure is present however, the 'Principle of Superposition' can become invalid due to the stiffening effect of the pressure, influencing the behaviour of the bend. The source of this nonlinearity is discussed further in section 3.7. Several early investigations $[4,22]$ into the behaviour of mitred pipe bends, wrongly assumed that, because all load/deformation curves were linear in their investigations into the individual loading cases, that the 'Principle of Superposition' could be used to determine the combined loading effect.

In his Master's thesis, So[26] carried out experiments on the combined effects of pressure and both in-plane and out-of-plane bending, for two single un-reinforced mitres. So observed that the effect of pressure, was more significant with larger a/t ratios. In addition, he observed that there was a progressive movement of the maximum stress location to the 'crotch' position, with increasing internal pressure. This is indicative of behaviour more and more akin to simple bending theory. 
More recently, Gresnigt[91] studied the elastic and plastic behaviour of single mitres with two different bend angles and radius to thickness ratios. The specimens were subjected to in-plane bending moments either opening or closing the bend angle, with either zero pressure or a fixed value of pressure. The author does not discuss the non-linear pressure stiffening effect, although there are significant differences in the flexibility factors, stress intensification factors and 'deformation capacities'.

Mark1[48] investigated the effect of a constant internal pressure on the cyclic in-plane and out-of-plane bending fatigue behaviour of multi-mitred bends. Markl reported that the resulting mean stress level had little effect on the magnitude of the fatigue stress concentrations. Although, from a comparison with the S-N curves without pressure, there was a trend present which indicated the increased significance of the constant pressure stresses as the applied variable bending stresses were reduced. This trend would become much more significant for bends with high $\mathrm{a} / \mathrm{t}$ ratios.

Lane[52] subjected a multi-mitre simultaneously to the action of in-plane bending and internal pressure. Lane reported that the results of the summation of the stresses obtained separately for external loading and with internal pressure, were in good agreement with those obtained in the tests in which the two types of loading were applied simultaneously. Therefore, Lane concluded that the 'Principle of Superposition' could be applied to multi-mitred bends for dimensions and loading conditions similar to those in the above tests. The above results were also reported by Lane \& Rose[54].

Bond[25] and Bond \& Kitching[62] reported the results of tests on a multi-mitred pipe bend when subjected to an in-plane bending load at various internal pressures. The results of these tests were compared with those derived from the theory produced by the same authors. The theoretical approach was similar to that used by Rodabaugh \& George[75], for the analysis of smooth bends. The authors concluded that the flexibility factor was not linearly related to pressure and that stress concentration factors due to bending were related to pressure in much the same way as were flexibility factors. Furthermore, it was found that the maximum stresses due to bending did not necessarily occur at the same location or in the same directions, for all pressures. Results obtained using the above theory, also compared favourably with the experimental results of Lane \& Rose[54].

Bond[25] and Kitching \& Bond[63], while investigating out-of-circularity effects, also considered the combined loading case of internal pressure and in-plane bending. The authors reported good agreement between theoretical and experimental results for stresses due to the bending moment and also for flexibility factors, when the specimen was subjected to in-plane bending in the presence of a constant internal pressure. Strains and deflections, in this case, were linear with bending moment for any given pressure. It was also reported that when the specimen was subjected to internal pressure only, or to internal pressure in the presence of a constant bending moment, the relationships between strains and pressure were non-linear. This non-linearity was thought to be caused by initial out-of-circularity of the pipe cross-section. The theoretical distributions bore only partial resemblance to the experimental distributions in this case. Finally, it was concluded that the total strains, due to combinations of internal pressure and in-plane bending, were found to be independent of the sequence of loading for the range of loads used. While this conclusion is true for the bends examined, it is generally dependent on the bend geometry and loading magnitudes [83].

Rodabaugh[28] discussed combined moment and pressure loading and from a comparison with the results of Bond \& Kitching[62], showed that the approximate expressions derived by Rodabaugh \& George[75], for the effect of internal pressure on the bending behaviour of smooth bends, could be used to assess the effects for multi-mitred bends. The work highlighted the reduction in maximum stress and flexibility with increase in pressure. It would appear from these results that use of the 'Principle of Superposition' to combine the 
effects of pressure and bending, will overestimate the actual stresses existing in a bend, especially for high a/t ratios.

The "User's Guide to Mitre" by Beveridge \& Carmichael[30], outlines how the 'Mitre' program may be used to determine the flexibility of, and stresses in, multi-mitred pipe bends subjected to internal pressure with or without in and/or out-of-plane bending. The program was derived from the work of Bond $[18,25]$. The status of this software is now unknown.

Ingenhousz[66], for a $90^{\circ}$ single-segment GRP mitre, found that the deformation due to combinations of pressure, moment and lateral force, was approximately the same as the sum of the deformations found for each of these loads separately.

Yousif \& Al-Dakhil[69], carried out combined pressure with in-plane and out-of-plane bending for a 3-segment and 5-segment mitre. Results were also compared with various theories. The authors concluded that the results obtained for the three different types of loading proved to be superimposable.

In his masters thesis, Lai[36], using finite element analysis, examined the effects of combined pressure and bending for two single segment mitred bends in the Hunterston 'A' nuclear power station. The finite element programme used did not cater for the 'non-linear' effect of combining pressure and bending and the author used the procedure developed by Rodabaugh[28] to modify the bending results, before algebraically adding to the pressure stresses. Results were compared with those from the 'Mitre' program [30] and it was concluded that the comparison was satisfactory. However, it was noted that simply adding, without factoring, provided a better comparison in this case.

Battle et al[79], reviewed the information available for the effects of pressure on the flexibility and stress intensification factors for mitred bends, while drafting amendment 3 to BS806:1975[98]. The working group noted the correlation between experiment and theory on this matter, but also noted that it would be inappropriate to recommend inclusion of this effect for mitred bends, when the code did not consider it for smooth bends. The matter was referred to the main standard committee for consideration. This standard has now been replaced by BSEN 13480[99] and it would appear that this effect of pressure has yet to be included.

In his $\mathrm{PhD}$ thesis, Babaii Kocheckseraii[83] examined combined pressure and bending loading of single mitred pipe bends using large displacement finite element methods. It was concluded that the final stress state was in fact dependent upon the loading sequence.

Babaii Kocheckseraii \& Robinson[94] using both experiment and finite element analysis, examined the combined effects of pressure and in-plane bending for a PVC (polyvinyl chloride) lined GRP multi-mitre. The authors concluded that only large displacement finite element analysis is suitable for the practical design of bends subjected to combined internal pressure and in-plane bending. The mechanism of non-linear interaction was beyond the scope of their study, but it was highlighted as being the subject of possible future study.

It is also worth emphasising the complications that the above effects introduce into the analysis of pipelines, especially lines containing pipes with large $a / t$ ratios. The fact that the pressure normally decreases the flexibility factor of the bend, actually results in an increase in the moments being applied to the bend (and of the terminal reactions).

To the author's knowledge, there are no published references pertaining to this subject in relation to single reinforced mitred bends. It is likely however, that the general observations for un-reinforced single and multi-mitres, reported above, will also be applicable to the reinforced case (the significance of the pressure-stiffening effect being less).

\subsection{End Effects and the Influence of Leg Length}

Two factors which affect the flexibility and hence stresses in pipe bends are the location of flanges and the length of 'tangent pipes'. Compared to a smooth pipe bend, the ovalisation of the cross section is reduced due to the mitre intersection and this leads to a further complication in the study of these effects. Zeno in a discussion of reference [49] presented 
results of a study carried out into the effects of tangent pipe length on the flexibility of a 4segment mitred bend. Zeno presented a graph which showed the variation of a 'flexibility ratio' with length of tangent pipes. From a consideration of this graph, it was apparent that only approximately $3 \%$ of the theoretical flexibility factor was developed, if flat plates were welded directly to the ends of the bend, i.e. zero tangent pipe lengths.

Mark1[1] observed that the effect of flanges attached directly to the ends of an elbow, cancelled a large part of the bends' inherent flexibility and at the same time reduced the associated stress concentration. Markl further suggested that the effect of straight tangents was of 'minor importance'. From a study of Zeno's discussion above, Markl suggested that a tangent length equal to at least two pipe diameters should exist between the bend and adjoining flanges or anchors, if the inherent flexibility of the bend was to be fully utilized.

Bond[18] considered the effect of 'leg length' on the behaviour of multi-mitred pipe bends. From his theoretical analysis, he suggested an expression which yielded a value for tangent pipe length which would ensure that the effects of flanges, etc. would be negligible. This length was derived from a consideration of pipe radial deformation. From a study of the results of the Lane \& Rose tests [54], which included various leg lengths, Bond could find no clear trend between leg length and flexibility factor. Bond also investigated the assumptions pertaining to the effect of tangent pipe length, contained in smooth bend analyses and observed that the 'rule of thumb' often adopted, that the leg length should be greater than three diameters, was not a function of wall thickness and may therefore be in error for large $a / t$ ratios.

Kitching \& Thompson[21] carried out an extensive investigation into the effect of 'leg length' on the flexibility of single un-reinforced mitres. Bond[25] considered the application of his multi-mitred pressure theory to single un-reinforced mitres. During his examination of this matter he considered experimental results from the literature for single mitres with both 'long' and 'short' leg lengths. He suggested that for mitres with 'short' leg lengths, the system of forces produced by end caps, flanges, etc. would not be negligible at the intersection. This would then necessitate the consideration of the bend unit as a whole, including the influence of the end fixings. From these comparisons, Bond suggested that for single mitres with a mitre angle of $45^{\circ}$, leg length was a significant factor affecting the stress distribution in bends of the 'short' category. For bends with a mitre angle less than $30^{\circ}$, however, he suggested that leg length was not a significant parameter. This study by Bond highlighted the fact that the pressure stress distributions in single mitred bends were not only a function of the pressure, mitre angle and $a / t$ ratio, but could also be a function of leg length and end fixing.

So[26], while studying single un-reinforced mitres, examined Kitching \& Thompson's[21] formulae for variable flexibility factor and derived suitable values for use with these formulae, for the mitres tested during his own investigation.

Intarangsi[78], carried out an elastic parametric survey of single mitres and reported results of a limited study of the effect of leg length (segment length) on maximum stress level for an a/t ratio of 20 over a range of bend angles. Maximum stress was found to relatively insensitive over this range of variables.

Lai[36], using finite element models, examined the effects of shortening the tangent pipe length and the addition of flanges, on the in-plane bending and pressure behaviour of a single segment mitred bend in the gas re-circulating ducts of the Hunterston 'A' nuclear power station. It was noted that these factors were not significant for pressure loading. However, for in-plane bending the stresses were significantly increased by the shortened tangent pipe and significantly reduced when a 'rigid' flange was attached.

Battle et al[79], reviewed the information available on attachments for mitred bends, while drafting amendment 3 to BS806:1975[98]. The working group noted the possible stiffening effect of rigid attachments on the flexibility of mitres, but also noted that it would be inappropriate to recommend inclusion of this effect on the flexibility and stress intensification 
factors for mitred bends, when the code did not make any provision for the effect for smooth bends. The matter was referred to the main standard committee for consideration. It was however noted that the code did make provision for correction of the stress intensification factor for flanged bends. This standard has now been replaced by BSEN 13480[99] and it would appear that the influence of "end-effects" has yet to be included.

\subsection{Thickness Variations and Out-of-Circularity}

In considering the information available on mitred pipe bends, it is apparent that several researchers have attributed the poor comparisons obtained between theoretical and experimental results to thickness variations and out-of-circularity in the experimental specimens. It was apparent from these discussions that the effect of out-of-circularity in particular, was far more important in the case of internal pressure loading than for any other loading type.

Bond[25] and Kitching \& Bond[63] examined a $90^{\circ}$, 2-segment mitre subjected to a combination of bending moments and internal pressure. When the bending moments were applied alone, the stress distributions and flexibility factors compared well with theoretical predictions. When internal pressure was applied alone and then combined with bending loads, significant non-linear elastic behaviour was observed. This behaviour was attributed to the initial out-of-circular shape of the pipe section.

Hose[84] and Kitching \& Hose[85] examined the strain distributions in five $90^{\circ} \mathrm{PVC}$ lined GRP 3-segment bends. The bends were subjected to the individual loading cases of inplane bending, out-of-plane bending and internal pressure. The $3 \mathrm{~mm}$ thick PVC liner was wrapped with E-glass CSM (chopped-strand mat) and the manufacturing process resulted in a variation in thickness around the bend profile (thicker at intrados and thinner at extrados). The authors discuss the thickness variation and make suggestions as to how to deal with this in their laminated shell finite element model. However, the theoretical results reported pertain to uniform thickness bends. The comparisons with experiment on this basis are reasonable. The authors also report a variation in the experimental results for nominally identical bends and this is attributed to variability in the manufactured specimens. While thickness variations had relatively little effect on the bending results, the authors report that a radius variation of only $1 \%$ can induce severe bending stresses for internal pressure loading.

\subsection{Creep}

The author is unaware of any investigations, experimental or theoretical, having been carried out into the creep behaviour of mitred bends. Several investigators [26, 25], during 'limit load' investigations, have reported 'cold creep' of the mitred specimens at loads greatly in excess of that required to cause yield. Hose[84] discusses the possible importance of creep on the interlaminar shear stress and modulus for GRP bends.

\subsection{Fatigue and Fracture Mechanics}

Markl[1] carried out fatigue tests (in-plane and out-of-plane bending), on $90^{\circ}$ single unreinforced mitred bends. Conventional S-N diagrams were presented and positions of fatigue crack failures indicated.

Markl[48, 1] carried out in-plane and out-of-plane bending fatigue tests on various multi-mitre specimens, including single, double and quintuple segment $90^{\circ}$ bends, with a range of 'crotch spacings'. As well as presenting conventional S-N diagrams, the positions and directions of fatigue cracks were discussed. Markl also investigated the effect of internal pressure, stress relieving and grinding of welds, on the fatigue life of the specimens. Macfarlane[55] investigated the fatigue behaviour of both single segment and double segment bends of varying radius of curvature. The tests consisted of both in-plane and out-of-plane actions. Macfarlane also conducted pulsating pressure fatigue tests on the single segment mitres. The various Piping Codes provide guidance in the use of mitred bends under cyclic load conditions. The information embedded in these Codes is based directly on these studies. 
Murray[96] tested 4 nominally identical bends subjected to internal pressure. Two of the bends were subjected to low cycle fatigue pressure cycles of 64000 and 100000 respectively. The magnitude of some alternating pressure components, superimposed on top of a mean pressure level would have been sufficient to cause yielding at the bend intersection. These two bends were then subjected to a static burst pressure. The cyclic pressure test results typically show a non-linear initial loading curve and a linear unloading curve, with a resulting residual strain on the gauges. For the second and all subsequent loadings the curves followed the first unloading curves, indicating that the residual stresses had shaken down. No discussion is presented on the presence of fatigue damage. The author's conclusion that the fatigue life of a welded mitre bend appears to be comparable to that of an equivalent straight pipe is unlikely to be of general applicability.

Bailey \& Boulton[72] report an investigation into the low cycle fatigue failure of a mitred joint in an oil pipeline and concluded from a fracture mechanics assessment, that a local stress concentration caused by severe misalignment was sufficient to cause crack growth and failure under the actual number of pressure cycles undergone. It was further concluded that the fatigue failure, which did not occur at the expected position of maximum stress, was due to the growth of existing hydrogen cracks in the weld material. These cracks were caused by the high restraint which resulted from severe misalignment of the mitre joint.

The former Central Electricity Generating Board in the UK conducted an extensive investigation into the effects of cracks in the vicinity of the intersection of the large diameter $90^{\circ}$ reinforced single mitres which formed part of the $\mathrm{CO} 2$ ducting of gas cooled nuclear reactors. This investigation was prompted by the discovery of cracks in these mitres at several power stations. As a result of this investigation, Connors et al[81] was able to present test results for a range of pressurised single mitred bends, reinforced with elliptical inserts of various thicknesses. Some of the bends had various pre-machined defects, at or near seam and butt welds or high stress regions. Tests to failure on these bends allowed the authors to develop fracture mechanics failure models and an assessment procedure based around R6[101]. The procedure was shown to produce conservative results. The fracture assessment procedure utilised linear elastic results and to this end, brick finite element models were also used to examine the effects of various geometrical variations. The experimental results were used to verify these basic models.

Wood[97] reports detailed strain gauge results for a $90^{\circ}$ single unreinforced mitre bend subjected to in-plane bending. The linear elastic results are compared with a highly refined thin shell finite element idealisation. The nature of the stresses at such intersections is discussed, as are various methods used to obtain fatigue "hot-spot" stresses.

\subsection{Non-linearity/Large Displacement/Plasticity/Failure}

The 'non-linear' effects which precluded the use of the 'Principle of Superposition' to mitred bends under pressure loading have already been discussed. The post-yield information available in the literature relates to either limit/burst pressure tests or limit/collapse bending moment tests - either in-plane or out-of-plane.

So[26] carried out a successful in-plane bending collapse test for a $90^{0}$ single unreinforced mitre pipe bend, manufactured from aluminium. Although not specifically mentioned, it would appear that the in-plane bending moment was tending to 'close the bend i.e. reduce the bend angle. A collapse load ' $\mathrm{F}_{\mathrm{L}}$ ' of $6161 \mathrm{~N}(1385 \mathrm{lbf})$ was reported for this test. This compared to a 'gross yield' load ' $\mathrm{F}_{\mathrm{GY}}$ ' of $1868 \mathrm{~N}$ (420lbf), giving an $\mathrm{F}_{\mathrm{L}} / \mathrm{F}_{\mathrm{GY}}$ ratio of 3.3 and a first yield ratio $F_{L} / F_{F Y}$ of 4.6. It was noted in this experiment that the load/deflection behaviour of the bend became time dependent at loads above $2002 \mathrm{~N}$ (450 lbf). The test on a $120^{\circ}$ bend was ended prematurely, due to a failure in the test arrangement.

Murray[27] reported a burst pressure ' $\mathrm{P}_{\mathrm{L}}$ ' of $7.2 \mathrm{~N} / \mathrm{mm}^{2}$ (1050psi) for a single unreinforced steel mitre. This value compared with a first yield ' $\mathrm{P}_{\mathrm{FY}}$ ' of $1.9 \mathrm{~N} / \mathrm{mm}^{2}$ (270psi), 
giving a $\mathrm{P}_{\mathrm{L}} / \mathrm{P}_{\mathrm{FY}}$ ratio of approximately 3.9. Regions of the bend were whitewashed and gross plastic deformation was observed at pressures above $5.5 \mathrm{~N} / \mathrm{mm}^{2}(800 \mathrm{psi})$. Using the 'mean diameter formulae' [73] for the calculation of the estimated bursting pressure of a straight circular cylindrical shell, manufactured from the same material as the bend, gives a value of $7.4 \mathrm{~N} / \mathrm{mm}^{2}$ (1080psi). This indicates that the burst pressure for the mitre bend, in this test, was approximately $97 \%$ of the burst pressure for the corresponding straight pipe. It should be noted that the materials (pipe and weld) used in the above specimens were ductile enough to accommodate the gross plastic deformation which took place.

The report of the Court of Inquiry into the Flixborough Disaster[29] contained some information on two series of tests carried out on mitred pipe bend arrangements. The investigations were concerned with establishing the strength of a temporary 'by-pass' pipe arrangement, the failure of which led directly to an explosion at the Flixborough Works of Nypro (UK) Ltd., in which 28 people were killed. The 'bypass' pipe arrangement consisted of two unreinforced mitred pipe bends welded in a 'dog-leg' fashion and connected to expansion bellows at the exit from each reactor vessel. Little information relating to actual 'by-pass' dimensions could be ascertained, but it would appear that the bend angle of each mitre was approximately $170^{\circ}$. The nominal pipe diameter was 20 -in., but unfortunately the wall thickness was not contained in the reference. In all, eight simulation tests were carried out. The tests carried out on the bend arrangement consisted of essentially internal pressure with an axial thrust applied along each leg, with balancing shear forces. The axial thrust was related to the internal pressure during most of the test and in the latter stages of the test, the relationship could not be held constant. For this pipe arrangement, the relationship between pressure and mitre deflection was linear up to a pressure of approximately $15 \mathrm{~kg} / \mathrm{cm}^{2}\left(\mathrm{P}_{\mathrm{GY}}=1.5 \mathrm{~N} / \mathrm{mm}^{2}\right)$. The maximum pressure the 'dog-leg' could sustain was $18.5 \mathrm{~kg} / \mathrm{cm}^{2}\left(\mathrm{P}_{\mathrm{L}}=1.8 \mathrm{~N} / \mathrm{mm}^{2}\right)$, giving an approximate $\mathrm{P}_{\mathrm{L}} / \mathrm{P}_{\mathrm{GY}}$ ratio of 1.2 .

Kitching, Rahimi \& So[70] used a shell finite element model to examine the post-yield behaviour of the two aluminium bends with unequal leg lengths, tested by SO and reported in reference [26]. The difference between the finite element and experimental results is appreciable and this was thought to be partly due to the fact that the finite element model assumed an elastic-perfectly plastic material model, whereas the real bend material showed significant strain hardening. In his $\mathrm{PhD}$ thesis, Rahimi[82] presents results for 3 stainless steel mitres, with different bend angles, under in-plane bending. The ratios of collapse moment to general yield moment were 2.7, 2.2 and 1.9 for the specimens with $90^{\circ}, 120^{\circ}$ and $150^{\circ}$ bend angles respectively. For a $90^{\circ}$ specimen with a reduced wall thickness in the vicinity of the intersection, the pressure test was not carried on until 'burst', due to a leak in the pressure system. Rahimi reported favourable comparison with large displacement finite element models and a lower bound theoretical solution.

A parametric survey for the in-plane limit moment of single mitres was presented by Robinson \& Babaii Kockekseraii[86]. The 'upper bound' results were obtained using shell finite element models. The lower bound theory presented represents an improvement on the theory reported in [83]. The same parametric results were also presented by Babaii Kockekseraii[93], along with a comparison against the experimental results of [70]. The importance of including large displacement effects in the analysis of bends with combined pressure and bending loads was highlighted by Babaii Kockekseraii [83] and the dependence of the final stress state on loading sequence was also illustrated.

In 2002, Gresnigt[91] presented elastic and plastic results for various single mitres when subjected to in-plane bending, with and without a fixed internal pressure. Although collapse loads and deformations are not discussed, the author presents both elastic and plastic 'limit' values. For the deformations, these limit values are in general much smaller than those at the end of the test. The ratio of plastic to elastic 'deformation capacity' varies between 4.7 
and 6.8 over the range of tests. In this case, the ratios relate to the angular rotation of the bend at a set distance from the mitre intersection, taken from the load-deflection plots at departure from linearity (elastic) and at maximum load (plastic). The cyclic load-deflection graphs clearly show ratchetting, although no comment is made on this behaviour or on the purpose of the cycling. It is also noted that the 'deformation capacity' of the mitres in bending, is considerably greater that that for a straight pipe.

Procter[42] carried out a burst test on a $90^{\circ}$ reinforced mitred pipe bend. The reinforcement of the bend consisted of an elliptical insert-cascade band $31.75 \mathrm{~mm}$ thick $(1.25$ inches) with external reinforcement. The actual profile of the external reinforcement is unclear, although it appeared to consist of two elliptical reinforcing rings, several inches apart and joined by a continuous band close to the outer rims. The maximum elastic S.C.F. obtained was 2.4. A strain/pressure graph indicated a departure from nonlinearity at approximately $2.8 \mathrm{~N} / \mathrm{mm}^{2}\left(\mathrm{P}_{\mathrm{FY}}=400 \mathrm{psi}\right)$. Limited surface yielding had probably occurred by this time at a few other positions on the bend however. The bursting pressure $\left(\mathrm{P}_{\mathrm{L}}\right)$ indicated for this bend was $9.6 \mathrm{~N} / \mathrm{mm}^{2}$ (1390psi), giving a $\mathrm{P}_{\mathrm{L}} / \mathrm{P}_{\mathrm{FY}}$ ratio of 3.5. From the pressure/volume graph, general yielding was shown to occur at approximately $5.4 \mathrm{~N} / \mathrm{mm}^{2}\left(\mathrm{P}_{\mathrm{GY}}=790 \mathrm{psi}\right)$, giving a $\mathrm{P}_{\mathrm{L}} / \mathrm{P}_{\mathrm{GY}}$ ratio of 1.8. From this graph, Procter reported that the volumetric strain was approximately $0.2 \%$ at yield and $13.1 \%$ at failure. The corresponding values for a straight pipe would be $0.22 \%$ and $13.7 \%$, indicating that the burst pressure for the bend was approximately $96 \%$ of that for the 'equivalent' straight pipe. The gross distortion evident at failure implied high ductility. Townley $\&$ Procter[43] also presented and discussed the implication of the tests reported in reference [42].

Vrillon, Roche \& Baylac[46] presented the results of a comparison between experimental and finite element results for two $90^{\circ}$ mitred bends reinforced with elliptical inserts. The report considers plastic behaviour, including shakedown. From the strain/pressure graphs and the bend angle/pressure variation, it would appear that the pressure level at the start of non-linear behaviour, for the bend with an a/t ratio of 25 , was 54 bar and for the bend with an a/t ratio of 43 , was 37 bar. The burst pressure for the specimen with an a/t ratio of 25 was not obtained. For the specimen, with an a/t ratio of 43 , the burst pressure was 125 bar $\left(\mathrm{P}_{\mathrm{L}}\right)$, giving a $\mathrm{P}_{\mathrm{L}} / \mathrm{P}_{\mathrm{FY}}$ ratio of approximately 3.4. An interesting observation made during these tests was that, for both bends, the internal pressure caused the bend angle to increase when the bend behaviour was elastic. When the bend behaviour became plastic however, the internal pressure caused the bend angle to decrease.

Gross[50] reported that a load of $6676 \mathrm{~N}$ ( 0.67 tons) was required for gross yielding of a $90^{0}, 5$ segment, mitre (indicated by a departure from linearity of the load/deflection graph). Unfortunately, Gross did not carry the above test to failure and therefore collapse loads could not be obtained. specimens:

Lane[52] reported the following results from tests to failure on $90^{\circ}$ double-segment

(i) In-plane Bending (reducing bend angle): First yield moment, indicated by strain gauges, ' $\mathrm{M}_{\mathrm{FY}}$ ' was $41759 \mathrm{Nm}$ (165 tons-in), whereas the collapse moment ' $\mathrm{M}_{\mathrm{L}}$ ' was $194271 \mathrm{Nm}$ (412 tons-in) giving an $\mathrm{M}_{\mathrm{L}} / \mathrm{M}_{\mathrm{FY}}$ ratio of 2.5 .

(ii) In-plane bending (increasing bend angle): The first yield moment ' $\mathrm{M}_{\mathrm{FY}}$ ' was $40241 \mathrm{Nm}(159$ tons-in). However, in this case, no failure was indicated at $264475 \mathrm{Nm}$ (1045 tons-in) and the test was discontinued.

This indicated an $\mathrm{M}_{\mathrm{L}} / \mathrm{M}_{\mathrm{FY}}$ ratio $>6.5$.

(iii) Internal Pressure: The first yield pressure ' $\mathrm{P}_{\mathrm{FY}}$ ' was $6.9 \mathrm{~N} / \mathrm{mm}^{2}$ (1000psi), whereas bursting ' $\mathrm{P}_{\mathrm{L}}$ ' occurred at $25.5 \mathrm{~N} / \mathrm{mm}^{2}$ (3700psi), giving a $\mathrm{P}_{\mathrm{L}} / \mathrm{P}_{\mathrm{FY}}$ ratio of 3.7 . This bursting pressure of $25.5 \mathrm{~N} / \mathrm{mm}^{2}$ (3700psi) for the mitred bend, compared with a burst pressure of $25.6 \mathrm{~N} / \mathrm{mm}^{2}$ (3720psi) for the equivalent straight pipe. 

mitres:

Lane[53] reported the following results from tests to failure on $90^{\circ}$ single segment a) In-Plane Bending (reducing bend angle): The general yield moment ' $\mathrm{M}_{\mathrm{GY}}$ ' indicated by nonlinearity of load/deflection plot, was $47833 \mathrm{Nm}$ (189 tons-in), whereas the collapse moment ' $\mathrm{M}_{\mathrm{L}}$ ' was $95160 \mathrm{Nm}$ (376 tons-in), giving an $\mathrm{M}_{\mathrm{L}} / \mathrm{M}_{\mathrm{GY}}$ ratio of 2.0 .

b) In-Plane Bending (increasing bend angle): The general yield moment ' $\mathrm{M}_{\mathrm{GY}}$ ' was approximately $97691 \mathrm{Nm}$ (386 tons-in). Unfortunately, during this test the rig failed, therefore precluding the determination of a collapse load. At the point of rig failure, the maximum moment applied was approximately $187284 \mathrm{Nm}$ (740 tons-in), therefore the $\mathrm{M}_{\mathrm{L}} / \mathrm{M}_{\mathrm{GY}}$ ratio was in excess of 1.9 .

c) Internal Pressure: The general yield pressure ' $\mathrm{P}_{\mathrm{GY}}$ ' was somewhere between $12.4 \mathrm{~N} / \mathrm{mm}^{2}$ (1800psi) and $13.4 \mathrm{~N} / \mathrm{mm}^{2}$ (1950psi), whereas bursting ' $\mathrm{P}_{\mathrm{L}}$ ' occurred at $20.0 \mathrm{~N} / \mathrm{mm}^{2}$ (2900psi), giving a $\mathrm{P}_{\mathrm{L}} / \mathrm{P}_{\mathrm{GY}}$ ratio somewhere between 1.6 and 1.5 . This bursting pressure of $20.0 \mathrm{~N} / \mathrm{mm}^{2}$ for the mitred bend, compares with a burst pressure of $24.5 \mathrm{~N} / \mathrm{mm}^{2}$ (3557psi) for the equivalent straight pipe. The above results were also reported by Lane \& Rose[54].

Bond[25] tested a $90^{\circ}, 2$-segment, mitre under the action of an in-plane bending load, tending to reduce the angle of the bend, until it collapsed. The salient points from the test were as follows:

1) Deviation from linearity of end deflection v load plot occurred at $2135 \mathrm{~N}$ (480 lbf). ' $\mathrm{F}_{\mathrm{GY}}$ '.

2) Collapse occurred at a total end load of $4239 \mathrm{~N}$ (953 lbf). ' $\mathrm{F}_{\mathrm{L}}$ ' giving an $\mathrm{F}_{\mathrm{L}} / \mathrm{F}_{\mathrm{GY}}=2$.

Murray[96] tested a wide range of $90^{\circ}$ multi-mitre bends subjected to internal pressure. As shown in Table 3, the test variables included number of segments, bend radius, grade of steel and to a lesser extent pipe mean radius to thickness ratio. Two nominally identical bends of each type were taken to burst. In all cases the bursting pressure of the welded mitres was greater than $90 \%$ of that for an equivalent straight pipe. The author suggests the use of a simple rule that the burst pressure of any mitre be taken as $90 \%$ of the bursting pressure of an equivalent straight pipe. While it is concluded that this observation would appear to hold for both mild steel and high tensile steel pipes, the following restrictions are suggested:

- The angle of deflection of the pipes (bend angle/number of segments) should not exceed $45^{\circ}$.

- The segment lengths should not be less than the mean radius of the pipe.

- The ductility of the pipe and weld materials should be high and allow plastic strains of the order of $14 \%$ before fracture.

Intarangsi[78], carried out a shell finite element plasticity study of various multi-mitres subjected to internal pressure and reported good agreement with available experimental results for some parameters. However, it was noted that a large strain and large displacement formulation would be necessary to predict accurate burst pressures. The need for a carefully controlled experimental benchmark, with welds ground flush, specimen stress relieved, accurate geometry and well-defined material properties, was also highlighted. The experimental results reported, were part of the larger series of tests carried out by Murray [96] and discussed above.

Hose[84] reported the failure of five nominally identical multi-mitre piped bends, with a PVC lined GRP construction as detailed in section 3.3. The failure mechanisms and appearances are discussed for in-plane bending, out-of-plane bending and internal pressure loading.

Most piping codes will attempt to ensure that the minimum thickness of the bend is such that it will guard against gross plastic deformation and will shakedown to elastic action within the first few cycles. Murali, Munshi \& Kushwaha[89] discussed the possible extension of the 'B' index for mitred bends in ASME III Boiler and Pressure Vessel Code NB3600[100], to $a / t$ ratios $>25$. The authors utilised finite element models with both geometric and material 
nonlinearity to examine the plastic buckling and collapse of a range of 2-segment mitres, with varying a/t ratio, under in-plane bending.

\subsection{Pre-stressing/Residual Stresses}

For bends with relatively high a/t ratios, a 'pre-stress' e.g. caused by internal pressure, may effectively alter both the static and dynamic response. The effect of internal pressure on the static response of mitred bends subjected to bending loads has already been discussed. In most cases, this effect is likely to be due to a large displacement effect rather than a pre-stress effect, although this is not discussed in any of the papers. These different non-linear effects are apparent in the following finite element relationship:

$$
d \psi=\left[K_{O}\right] d\{\delta\}+\left[K_{L}\right] d\{\delta\}+\left[K_{\sigma}\right] d\{\delta\} \text { where } \psi \text { is the vector sum of internal and }
$$

external forces; $\left[K_{O}\right]$ is the small displacement stiffness matrix; $\left[K_{L}\right]$ is the stiffness matrix due to large displacements; $\left[K_{\sigma}\right]$ is the initial stress or geometric matrix and $\{\delta\}$ is the vector of nodal displacements. It may be noted that $\left[K_{\sigma}\right]$ does not contain the displacements and is proportional to the stress level. Also, $\left(\left[K_{O}\right]+\left[K_{L}\right]\right)$ is what would be obtained using an incremental infinitesimal strain approach, while adjusting the element coordinates in the computation of stiffness. The 'large displacement' solution routine in finite element systems does not always involve the calculation of $\left[K_{\sigma}\right]$.

Many of the mitred bends outlined in tables 1-3 were stress relieved before testing. Markl[48] however, was the only author to investigate the effects of this on the behaviour of a bend. Markl investigated the effects of stress-relieving on the 'fatigue life' of various specimens. The comments of Intarangsi[78] in relation to the effects of residual stresses on his experimental results are noted in section 3.6. To the author's knowledge, no other references pertaining to this subject, for mitred piped bends, are available.

\subsection{In-Plane Bending/Opening v Closing}

From discussions relating to the elastic behaviour of mitred bends, it is apparent that there is no difference (apart from a change of sign) between moments tending to increase the bend angle and those tending to decrease it. This was also shown to be the case in the finite element analyses described in reference [35]. In contrast to this, discussion of the post-yield behaviour of mitres $[26,70,82,83,84,85,91,93]$ clearly indicates that there is a substantial difference in the moments required to produce collapse. The collapse moment for 'opening the bend' being much greater than that for 'closing the bend'. Interestingly, Hose[84] reports a nonlinear load deflection curve at all load levels, for an in-plane bending moment closing the bend angle, for a PVC lined GRP bend. For the case on an opening bend angle, the corresponding curve was linear until initial failure of the laminate.

\subsection{Pressure Loss/Flow Characteristics in Mitred Bends}

No attempt has been made in this review to investigate this aspect of mitred bends. Suffice to say that this topic has received its fair share of attention in the literature. It is however worth highlighting several features of mitre design and analysis which have resulted from these studies.

The pressure distribution in most mitred bends in a pipeline or ducting system will be nonuniform, due to flow characteristics. This variation has been neglected in all stress analyses of mitred bends so far undertaken. Finite elements would be extremely useful in the analysis of a bend with some significant variation in pressure. Today, fluid-structure interaction software provides the means of predicting such a pressure variation, as well as analyzing the structural behaviour of the mitre resulting from the distribution.

Bowden \& Drumm[76] discussed the design and testing of the large CO2 ducts for gascooled nuclear reactors. In this discussion, they emphasised the requirement for low pressure drop. The authors reported that at that time (1960), in a large power station, an expenditure of up to $£ 5000$ on each heat exchanger circuit could have been justified for any design feature which would have reduced the circuit pressure drop by $689.5 \mathrm{~N} / \mathrm{m}^{2}(0.1 \mathrm{psi})$. If one considered a 
typical station with eight heat exchanger circuits per reactor and perhaps two reactors, the financial incentive to reduce circuit pressure drop must have been great. This requirement for low pressure drop led to the incorporation of guide vanes at the intersection of the $90^{\circ}$ mitres incorporated in these nuclear stations. The need to inspect highly stressed bends was also considered in the duct layout.

Papers in this section have not been included in Tables 1-3.

\subsection{Anisotropy/Orthotropy}

Non-isotropic material behaviour can only complicate the analysis of any pressure component - anisotropy being the more general and most difficult case to analyse. Today, finite element analysis presents a feasible approach to the analysis of mitred bends involving such complexity. In this case however, obtaining accurate material models to use in the finite element analysis is often still a significant challenge.

Ingenhousz[66], Hose[84], Kitching \& Hose [85], Babaii Kochekseraii[83] and Babaii Kochekseraii \& Robinson[94] conducted experiments on PVC-lined GRP multi-mitred bends. However, in all cases, the GRP lay-up was assumed quasi-isotropic. The finite element models of the lined bends utilised 2-ply (GRP and PVC) laminated shell elements, with the PVC ply also being assumed isotropic. The lay-up process leads to a general rounding of the mitre intersection, particularly at the intrados. Hose[84] notes that single mitres are often not attractive for GRP due to the sharp angles and resulting problems forming the matt. The need to reduce the stress concentration due to the 'brittle' nature of GRP also leads to preferential use of multi-mitres.

Piping Codes provide some guidance in the use of mitred bends manufactured from non-metallic materials or lined with non-metals.

\subsection{Vibration}

This topic, in relation to mitre bend design, appears to have received little or no attention in the U.K. In contrast to this, the designers of the gas circuits of some French nuclear reactors appear to have given the topic considerable thought in the past. Baylac \& Copin[74] investigated the vibration characteristics of the primary gas circuit for the Chinon 3 nuclear reactor. In particular, they investigated the vibration induced stresses in the $90^{\circ}$ single-segment mitred bends which form part of the primary gas circuit in the graphite-gas nuclear reactor. The investigation included the internal guide vanes present to reduce pressure losses. The mitred bends were considered as a source of noise, as a position of noise amplification and finally as an area of special interest in relation to the response of the structure. The dynamic analysis of the behaviour of the piping showed that heat exchanger and mitred bend excitations had no effect. The only significant excitation was introduced by the blower vibration, which gave a maximum stress level of $20 \mathrm{MN} / \mathrm{m}^{2}$ in certain mitred bends. This paper provides a number of other references (in French), relating to the vibration of vaned bend components in the Chinon gas circuits. These references have not been included in this review.

\subsection{Optimisation}

The author is unaware of any optimisation studies of mitred pipe bends. Holland[20] derived theoretical stress equations for the pressure loading of a mitred bend reinforced with an elliptical ring and suggested that there was probably an optimum shape for the outer contour of this ring which, on a weight-for-weight basis, would provide lower stressing of the structure. Ingenhousz[66] using a $90^{\circ}$ single segment GRP mitre, examined several methods of design improvement. These improvements consisted of methods of reducing the stresses at the intersection via reinforcement. The reinforcement consisted of two increases in wall thickness. The first, was an overall increase in thickness of $5.8 \mathrm{~mm}$. The second was a further $5.8 \mathrm{~mm}$ increase in thickness in a region $\pm 60^{\circ}$ of the crotch position, over the whole length of the bend. Ingenhousz subjected the mitre bend to an internal pressure, in-plane bending moment and an in-plane force, individually and in combination. Perhaps not surprisingly, Ingenhousz 
concluded that the 'local' increase in thickness resulted in a more efficient utilisation of material than the 'overall' increase.

Clearly the possibility of optimising both the shape of any reinforcing ring and the thickness profile of any mitred bend exists. Other optimisation scenarios can no-doubt be postulated.

\section{Conclusions}

A comprehensive review of literature available on all aspects of mitred bend behaviour reveals that there is no theoretical solution available which is applicable to the complete range of bends found in industry. The review shows that all theories so far developed have limitations with varying implications on loading type, bend type and dimensions. Presently, the finite element method is perhaps the only method that is demonstrably applicable to the complete spectrum of mitred bends, materials and loading conditions.

Comprehensive design curves do not exist for the elastic and plastic behaviour of all mitre types, over a practical range of geometry and loading parameters. Similarly, there is still scope for further work on the effect of combined loading, end effects and out-of-circularity. Limit, collapse and burst loads are not yet available across the entire spectrum of bends and loading parameters either. Creep and optimisation represents virgin territory as far as mitred bends are concerned and given that unforeseen vibration is a common source of high-cycle fatigue failure in pipework, there must also be scope for vibration induced fatigue studies.

\section{Acknowledgements}

I would like to acknowledge the invaluable advice and assistance of my former mentor and friend Professor George Findlay. 


\section{Mitre Bend References}

1. Markl, A.R.C. Fatigue Tests of Piping Components. Trans of A.S.M.E. pp 287-303, April 1952.

2. Van der Nuet, A. Bending at the Oblique End Section of Cylindrical Shells. Proc. Sump. Theory of Thin Elastic Shells, ed. W T Koiter, North Holland Publishing Co, Amsterdam, 1960.

3. Green, A.E. and Emmerson, W.C. Stresses in a Pipe with a Discontinuous Bend. J. Mech. Phys. Solids, Vol. 9, pp 91-104, 1960.

4. Basso, G.L. Stress Studies on Thin-Walled Single Mitred Pipe Bends. MSc Thesis, Univ. of London, Jan. 1961.

5. Mackenzie, A.C. and Beattie, I.M. The Right-Angled Corner in a Large Diameter Pressure Ducting. Some Experimental Stress Analysis Results and Comparisons with Theory. Proc. of symp. on Pressure vessel Research Towards Better Design, I.Mech.E. Paper 7, 1961.

6. Emmerson, W.C. A Theoretical and Experimental Investigation of the Stresses in Mitred Joints in Thin Walled Ducting of Circular Section. Ph.D. Thesis, Univ of Durham, April 1962.

7. Purohit, B.K. A Study of a Right-Angled Mitred Pipe Bend Under In-Plane Bending. MSc. Thesis, Univ of Manchester, 1962.

8. Holland, M. Investigation of the Stresses at a Mitre-Joint with Stiffening Ring. MSc. Thesis, Univ of Durham, Nov. 1962.

9. Murthy, M.V.V. Stresses in a Mitred Pipe Joint Due to Internal Pressure or Pure Bending. National Aeronautical Laboratory, Bangalore, India, Technical Note No. TN-SA-4-63, May 1963.

10. Owen, B.S. and Emmerson, W.C. Elastic Stresses in Single Mitred Bends. J. Mech. Eng. Sci., Vol; 5, No.4, 1963.

11. Murthy, M.V.V. Stresses in a Mitred Pipe Joint Under Uniform Internal Pressure. Int. J. Mech. Sci, Vol. 6, pp 361-370, 1963.

12. Owen B.S., Holland, M. and Emmerson, W.C. Stresses in and Flexibility of Mitred Bends and Lobster-Back Bends. Proc. I. Mech. E.,Vo1. 178, pt. 3F, Paper 12, 1963.

13. Jones, N. A Study of a Right Angled Single Mitred Bend Subjected to Various Bending Moments. PhD Thesis, Victoria Univ. of Manchester, 1965.

14. Jones, N. and Kitching, R. An Experimental Investigation of a Right-Angled Single Unreinforced Mitre-Bend Subjected to Various Bending Moments. J. of Strain Analysis, Vol. 1, No.3, pp 248-263, 1966.

15. Jones, N. and Kitching, R. A Theoretical Study of In-Plane Bending of a Single Unreinforced Mitred Bend. J. of Strain Analysis, Vol. 1, No.3, 1966.

16. Jones, N. On the Design of Pipe Bends. Nuclear Engineering \& Design, 13 Sept. 1966.

17. Sobieszczanski, J. Koncentracja Naprezen I Odkszatlcenia Lonka1ne W Zalamaniach Rurociagu Cienkosciennego. PhD Thesis, Instytut Gospodarki Komunalnej, 1967.

18. Bond, M.P. The In-Plane Bending of Multi-Mitred Pipe Bends. MSc Thesis, Victoria Univ. of Manchester, Inst. of Sci. \& Tech., 1969.

19. Murthy, M.V.V. Stresses at the Intersection of Two Cylindrical Shells of Equal Diameter. Int. J. Solids Structures, Vol. 5, pp 879-892, 1969.

20. Holland, M. A General Analysis of a Reinforced Discontinuous Bend. PhD. Thesis, Regional College of Technology, Liverpool, July 1969.

21. Kitching, R. and Thompson, W.J. In-Plane Bending of Single Unreinforced Mitred Pipe Bends. J. of Strain Analysis, Vol. 5, No.1, 1970.

22. Sobieszczanski, J. Strength of a Pipe Mitred Bend. J. of Engineering for Industry, Nov. 1970. 
23. Rodabaugh, E.C. and Pickett, A.G. Survey Report on Structural Design of Piping Systems and Components. TID-25553, Oak Ridge National Lab., USA, Dec. 1970.

24. Bond, M.P. and Kitching, R. Multi-Mitred and Single Mitred Bends Subjected to Internal Pressure. J. Mech. Sci., Vol. 13, pp 471-488, 1970.

25. Bond, M.P. A Theoretical and Experimental Investigation of Multi-Mitred Pipe Bends Subjected to Various Types of Loading. PhD Thesis, Victoria Univ of Manchester, Inst. of Sci, \& Tech. Feb. 1971.

26. So, H.S. Single Mitred Pipe Bends Under Bending and Internal Pressure Loads. MSc. Thesis, Victoria Univ of Manchester, March 1971.

27. Murray, N.W. Bursting Test on a Bend in a Large Pipe. Civil Eng. Trans. Australia, Oct 1972.

28. Rodabaugh, E.C. Review of Data on Mitre Joints in Piping to Establish Maximum Angularity for Fabrication of Girth Butt Welds. WRC Bulletin 208, Aug. 1975.

29. H.M.S.O. The F1ixborough Disaster - Report of the Court of Inquiry, 1975.

30. Beveridge, D.C. \& Carmichael, G.D.T. Users Guide to 'Mitre' a Stress Analysis Program for Mitred Pipe Bends. CEGB Report RD/B/N4196, Dec. 1977.

31. Carmichael, G.D.T. \& Beveridge, D.C. Structural Assessment of Mitred Bends. A Survey of Experimental Data and Comparison with Results from 'Mitre' a Stress Analysis Program. CEGB. Report RD/B/N4252, March 1978.

32. Wang, I.C., Chen, H. and Liu, C.R. Mitred Joint of Two Cylindrical Shells Intersecting at an Arbitrary Angle. Trans. 4th. Int. Conf. on Pressure Vessel Tech. Paper C92/80, London, 1923 May 1980.

33. Chan, A.W. Sanders, J.L. Analysis of a Mitred Joint in a Cylindrical Shell in Bending. Int. J. Mech. Sci.,Vo1. 22, pp 621-636, 1980.

34. Sawa, Yoshiaki. Photoelastic Investigation of the Stresses in Mitred Bent-Cylinders Under Bending (Bend Angle $0=90^{\circ}$ ). Bulletin of the J.S.M.E., Vo1. 25, No. 209, pp 1662-1667, Nov. 1982.

35. Wood, J. A Study of Single Mitre Pipe Bends. PhD Thesis, Paisley College of Technology, April 1983.

36. Lai, A.K.F. A Finite Element Analysis of a Multi-Mitred Bend in the C02 Ducting at Hunterston Nuclear Power Station. MSc Thesis, Paisley College of Technology, Dec. 1983.

37. Findlay, G.E. and Wood, J. A Study of Single Mitre Pipe Bends Using the Finite Element Method. Proceedings of Conf. on Pipework Design and Operation, Institution of Mechanical Engineers, Paper C13/85, 19-20 Feb 1985.

38. Appleyard, W. Bending Moment, Tension and Shear at Mitred Junction of Two Cylindrical Pressure Vessels. Royal Aircraft Establishment, Farnborough, Technical Note Aero 1906, July 1947.

39. Kornecki, A. Stress - Strain State in a Thin-Walled Tube Rigidly Fixed in an Oblique Cross Section. Rozpr. Ing., Vol. 5, No.1, pp 119-134, 1957.

40. Dickson, J.I. and Forsythe, A.J. Reactor Circuit Aerodynamic Cornerpiece Tests on Fully Reinforced prototype. B \& W Research Dept. Report, 25 May 1959.

41. Estrin, M.J. Analysis of a Cylindrical Shell Clamped along an Oblique Contour. AKAD. NAUK. SSSR. OTD. TEKH. MEKH. MASH., pp 151-155, British Library English Translation No. RTS 2498 (Eng), 1959.

42. Procter, E. Tests to Destruction on a $6 \mathrm{ft}$ 6in dia. Cascade Corner Unit. C.E.G.B. Report No. RD/B/N.51, Aug. 1962.

43. Townley, C.H.A. and Procter, E. Over Pressure Tests on a Prototype Duct Corner Unit. The Engineer, Dec. 1963.

44. Corum, J.M. A Theoretical and Experimental Investigation of the Stresses in a Circular Cylindrical Shell with an Oblique Edge. Nuclear Eng. \& Design, 3, pp 256-280,1965. 
45. Holland, M., Barlow, N. and Mitchell, H. Reinforced Discontinuous Bend Subjected to Uniform Internal Pressure : Effect of Reinforcing Ring Stiffness. J. of Strain Analysis, Vol. 8, No.2, 1973.

46. Vrillon, B., Roche, R. and Baylac, G. Comparison Between Experimental and Computer Analyses of the Behaviour Under Pressure of a $90^{\circ}$ Bend with an Elliptical Section. 2nd Int. Conf. Press. Vess. Tech., San Antonio, Texas, 1-14 Oct. 1973.

47. Holland, M. Pressurized Right Angled Reinforced Discontinuous Bend: Effect of Reinforcing Ring Displacement. J. of Strain Analysis, Vol. 10, No.2, 1975.

48. Markl, A.R.C. Fatigue Tests of Welding Elbows and Comparable Double-Mitre Bends. Trans. of A.S.M.E.,Vol. 69, 1947.

49. Pardue, T.E. and Vigness, I. Properties of Thin-Walled Curved Tubes of Short-Bend Radius. Trans. of A.S.M.E., Jan. 1951.

50. Gross, N. Report on a Stainless Steel Lobster-Back Duct (Expt. 21). B.W.R.A. Confidential Report FE16/12/51, 1951.

51. Gross, N. and Ford, H. The Flexibility of Short-Radius Pipe Bends. I.Mech.E., Proc. (B), Vol. IB, pp 480-509, 1952.

52. Lane, P.H.R. The Design of Fabricated Pipe Bends, Part 1 : Experimental Stress Analysis of a Three-Weld Gusseted Bend. B.W.R.A. Confidential Report FE16/39/56, June 1956.

53. Lane, P.H.R. The Design of Fabricated Pipe Bends and Experimental Stress Analysis of 2Weld Gusseted Bends. B.W.R.A. Confidential Report FE16/46/57, Dec. 1957.

54. Lane, P.H.R. and Rose, R.T. Experiments on Fabricated Pipe Bends. B.W.R.A. Report No. D5/12/60, 1960.

55. Macfarlane, D.S. Fatigue Strength of Gusseted Pipe Bends. B.W.R.A. Report No. 03/19/61, 1962.

56. Kitching, R. A Study of Edge Deformations of Thin Cylindrical Shells as Applied to a Mitre Bend Subjected to an In-plane Bending Moment. PhD. Thesis, Univ. of Manchester, Apr 1964.

57. Kitching, R. Mitre Bends Subjected to In-Plane Bending Moments. Int. J. Mech. Sci.,Vol. 7, pp 551-575, 1965.

58. Kitching, R. In-Plane Bending of a $180^{\circ}$ Mitred Pipe Bend. Int. J. Mech. Sci., Vol. 7, pp 721-736 1965.

59. Kitching, R. and Bond, M.P. Flexibility and Stress Factors for Mitred Bends Under InPlane Bending. Int. J. Mech. Sci, Vol. 12, pp 267-285, 1969.

60. Bond, M.P. and Kitching, R. Computation of Stresses and Flexibilities for Multi-Mitred Pipe Bends Under In-Plane Bending. J. of Strain Analysis, Vol. 6, No.2, 1971.

61. Bond, M.P. and Kitching, R. Stress and Flexibility Factors for Multi-Mitred Bends Subjected to Out-of-Plane Bending. J. of Strain Analysis, Vol. 6, No.4, 1971.

62. Bond, M.P. and Kitching, R. Stress and Flexibility Factors for Multi-Mitred Pipe Bends Subjected to Internal Pressure Combined with External Loadings. J. of Strain Analysis, Vol. 7, No.2, 1972.

63. Kitching, R. and Bond, M.P. Out-of-Circularity Effects in a Pipe Bend Subjected to Pressure and Bending Loads. J. of Strain Analysis, Vol. 7, No.4, 1972.

64. Edwards, G. Cylindrical Shell Hybrid Finite Elements. PhD Thesis, Univ. of Nottingham, 1974.

65. Pan, Y.S., Anderson, T.L. and Skopp, G.H. Three-Dimensional Stress Analysis of Mitred Elbows. Int. J. Press. Vess. \& Piping, (4), 1976.

66. Ingenhousz, A.J. GRP Mitred Pipe Bend, Proc. 2nd Int Conf on Composite Materials, Toronto, Canada, 16-20 April 1978.

67. Watanabe, O. and Ohtsubo, H. Stress Analysis of Mitred Bends by Ring Elements (1st Report, Fundamental Theory). Trans. J.S.M.E., Vol. 47, Pt. 421A, pp 916-926, 1981. 
68. Watanabe, O. and Ohtsubo, H. Stress Analysis of Mitred Bends by Ring Elements (2nd Report, Parametric Survey of Stress Intensification \& Bending Flexibility). Trans. J.S.M.E. Vol 47, pt 421A, pp 927-935, 1981.

69. Yousif, A.E. and Al-Dakhil, M.H. Stress Analysis of Multi-Mitred Pipe Bends Subjected to an In- and Out-Plane Bending \& Internal Pressure. Proc. Soc. for Expt. Stress Analysis, pt 1, pp 301-308, 23-28 May 1982.

70. Kitching, R., Rahimi, G.H. and So, H.S. Plastic Collapse of Single Mitred Pipe Bends. Int. J. Pres. Ves. \& Piping, 38, pp129-145, April 1989.

71. Watanabe, O. and Ohtsubo, H. Stress Analysis of Mitred Bends by Ring Elements. J of Pressure Vessel Technology, Trans. A.S.M.E., Vol. 106, pp 45-62, 1984.

72. Bailey, N and Boulton, C.F. Misalignment and Cracking. The Welding Institute Research Bulletin, April, 1976.

74. Baylac, G and Copin, A. Vibration Studies of the New Primary Circuit of the Chinon 3 Reactor. Trans. ${ }^{\text {rd }}$ Int. Conf. on Struct. Mech. In React. Tech., Paper F4/3, London, 1-5 Sept, 1975.

77. Kitching, R Smooth and Mitred Pipe Bends. Ch.7, The Stress Analysis of Pressure Vessels and Pressure Vessel Components, Ed. Gill S.S., Pergamon Press, 1970.

78. Interangsi, A. The Finite Element Analysis of Mitre Bends. PhD Thesis, Monash University, Australia, 1981.

79. Battle, K., Carmichael, G.D.T, Creswell, E., Morse, D., Porter, H., Popplewell, P.L. and Riley, K. The Design of Mitred Bends - A Background to BS806:1975 Amendment No.3. Proc. Conf. on Pipework Design and Operation, IMechE, London, 19-20 Feb., 1985.

80. Sykes, A. Calculation of Stress Distributions in Single Mitred Unreinforced Pipe Bends Due to Bending or Pressure. MSc Thesis, University of Manchester, 1988.

81. Connors, D.C., Nash, P.R. and Oldale, M.C. Some Stress Analysis and Failure Results for $90^{\circ}$ Mitre Bends. Proc. Int. Conf. on Pipework Engineering and Operation, Paper C376/045, pp209-216, IMechE, 1989.

82. Rahimi, G.H. Elastic-Plastic Behaviour of Mitred Pipe Bends. PhD Thesis, University of Manchester, 1991.

83. Babaii Kochekseraii, S. Mitred Pipe Bends Subject to Internal Pressure and In-Plane Bending Moment, PhD Thesis, University of Manchester, 1994.

84. Hose, D.R. Glass reinforced plastic pipework of mixed wall construction. $\mathrm{PhD}$ Thesis, University of Manchester, January 1988.

85. Kitching, R. and Hose, D.R. Experimental and Theoretical Stress Analysis of Multi-Mitred Lined Glass Reinforced Plastic Pipe Bends. Int. J. Mech. Sci., v37, pp97-119, 1995.

86. Robinson, M. and Babaii Kochekseraii, S. Parametric Survey of Upper and Lower Bound Limit In-Plane Bending Moments for Single Mitred Pipe Bends of Various Geometries. Int. J. Pres. Ves. \& Piping, v79, pp735-740, 2002.

87. Sawa, Yoshiaki. Photoelastic Investigation of the Stresses in Mitred Bent-Cylinders Under Bending II (For Various Bent-Angles). Bulletin of the J.S.M.E.,Vo1. 27, No. 229, pp 13391345, Jul. 1984.

88. Sawa, Yoshiaki. Photoelastic Stress Analysis in Mitred Bend Under Internal Pressure (In Japanese). Bulletin of the J.S.M.E.,Vo1. 53, No. 496, pp 2416-2421, Dec. 1987.

89. Murali, B., Munshi, D., Vaze, K.K. and Kushwaha, H.S. Evaluation of Primary Stress Indices for Mitre Bends and Possibility of Extending to DO/T $>50$. Paper F02/4, SMIRT 12, Stuttgart, Aug. 15-20, 1993.

90. Khathlan, A.A. and Shazali, A. Elasto-plastic Analysis of Single Mitred Bends. Proc. Conf. on Developments in Computational Techniques for Civil Engineering, Edinburgh, Aug. 28-30, 1995. 
91. Gresnigt, A.M. Elastic and Plastic Design of Mitred Bends. Proc. $12^{\text {th }}$ Int. Offshore and Polar Engineering Conf., Kitakyushu, Japan, May 26-31, 2002.

93. Babaii Kochekseraii, S. Finite Element Modelling of Plastic Collapse of Metallic Single Mitred Pipe Bends Subject to In-Plane Bending Moments. Int. J. Pres. Ves. \& Piping, v81, pp75-81, 2004.

94. Babaii Kochekseraii, S. and Robinson, M. Flexural Behaviour of a Polyvinyl ChlorideLined Glass Reinforced Plastic Composite Multi-Mitred Pipe Bend Subjected to Combined Loads: A Comparative Finite Element Analysis and Experimental Case Study. J. Strain Analysis, v39, n2, pp137-146, 2004.

95. Skopinsky, V.N. and Mellerovich, G.M. A Numerical-Experimental Study of the Stress State of Pipeline Joints. Strength of Materials, v20, n12, pp1631-1634, 1988.

96. Murray, N.W. Bursting Tests on Welded Mitred Bends for Gas Pipelines. Aust. Welding Research, 7, pp1-26, April 1979.

97. Wood, J. Stresses in the Vicinity of an Un-reinforced Mitre Intersection: An Experimental and Finite Element Comparison. Journal of Strain Analysis for Engineering Design, v42, n5, pp325-336, 2007.

\section{Non-Mitre Bend and Mitre Bend Non-Structural References}

76. Bowden, A.T. and Drumm, J.C. Design and Testing of Large Gas Ducts. Proc. IMechE, Vol.174, No.3, 1960.

73. Roark, R.J. and Young, W.C. Formulas for Stress and Strain, $5^{\text {th }}$ Ed, McGraw-Hill, 1975. 75. Rodabaugh, E.C. and George, H.H. Effect of Internal Pressure on Flexibility and Stress Intensification Factors of Curved Pipe or Welding Elbows. Trans. of ASME, Vol.79, 1957.

92. Henderson, M.A., Alberti, S., Bird, J., Doane, J., Elzendoorn, B., Flemming, C., Goodman, T.P., Hoekzema, F., Hogge, J.P., MacMillan, G., Magnin, J.C., Pioscyk, B., Porte, L., Tran, M.Q. and Verhoeven, A.G.A. An ITER-Relevant Evacuated Waveguide Transmission System for the JET-EP ECRH Project. Nuclear Fusion, v43, pp1487-1500, 2003.

98. BSI. BS806: Specification for Design and Construction of Ferrous Piping Installations for and in Connection with Land Boilers, 1975.

99. BSI. BSEN 13480 Series: Metallic Industrial Piping, 2002.

100. American Society of Mechanical Engineers. ASME Boiler and Pressure Vessel Code Section III, Division 1: Rules for Construction of Nuclear Facility Components, Class 1 Components, Subsection NB3600: Piping Design, 1990.

101. Milne, I., Ainsworth, R.A., Dowling, A.R. and Stewart, A.T. Assessment of the Integrity of Structures Containing Defects, CEGB Report R/H/R6 Revision 3, 1986. 


\begin{tabular}{|c|c|c|c|c|c|c|c|c|c|c|c|c|c|c|c|}
\hline \multirow{3}{*}{ 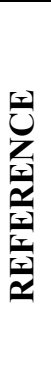 } & \multicolumn{2}{|c|}{ NATURE } & \multicolumn{9}{|c|}{ LOADING } & \multicolumn{4}{|c|}{$\begin{array}{c}\text { EXPERIMENTAL } \\
\text { SPECIMEN DETAILS }\end{array}$} \\
\hline & & & \multicolumn{2}{|c|}{ IPB } & \multicolumn{2}{|c|}{ OPB } & \multicolumn{2}{|c|}{ TORS } & \multicolumn{2}{|c|}{ PRESS } & \multirow{2}{*}{ 愛 } & \multirow{2}{*}{$\begin{array}{c}\text { BEND } \\
\text { ANGLE } \\
\text { (degrees) } \\
*_{1}\end{array}$} & \multirow{2}{*}{$\begin{array}{c}\text { Mean } \\
\text { pipe } \\
\text { radius } \\
\quad \mathbf{a} \\
\\
(\mathrm{mm})\end{array}$} & \multirow{2}{*}{$\begin{array}{c}\text { Pipe wall } \\
\text { Thickness } \\
\text { t } \\
(\mathrm{mm})\end{array}$} & \multirow[b]{2}{*}{$\mathbf{a} / \mathbf{t}$} \\
\hline & $\frac{.0}{\mathscr{0}}$ & 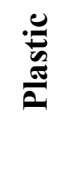 & 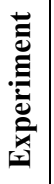 & $\stackrel{0}{D}$ & 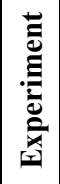 & $\underset{\mathscr{e}}{\stackrel{d}{0}}$ & 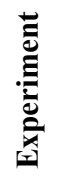 & 莺 & 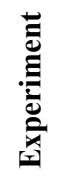 & 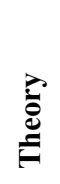 & & & & & \\
\hline 1 & $\#$ & & $\#$ & & $\#$ & & & & & & & 90 & 54.10 & 6.10 & 9 \\
\hline 2 & $\#$ & & & & & & & & & $\#$ & & & & & \\
\hline 3 & $\#$ & & & \# & & & & & & $\#$ & & & & & \\
\hline 4 & $\#$ & & $\#$ & & & & & & & & & 90 & 37.34 & 1.52 & 24.5 \\
\hline 5 & $\#$ & & & & & & & & $\#$ & & & 90 & 1001 & 35 & 28.7 \\
\hline 6 & $\#$ & & $\#$ & $\#$ & & & & & $\#$ & $\#$ & $* 8$ & $(90,105,120,150)$ & 50.8 & $\begin{array}{l}2.54 \\
5.08\end{array}$ & $\begin{array}{l}20 \\
10\end{array}$ \\
\hline 7 & $\#$ & & \# & $\#$ & & & & & & & & 90 & 106.93 & 5.59 & 19 \\
\hline 8 & $\#$ & & $\#$ & & & & & & $\#$ & & & 90 & 50.8 & 5.08 & 10 \\
\hline 9 & $\#$ & & & $\#$ & & & & & & $\#$ & & & & & \\
\hline 10 & $\#$ & & $\#$ & & & & & & $\#$ & $\#$ & $* 8$ & $(90,105,120,150)$ & 50.8 & $\begin{array}{l}2.54 \\
5.08 \\
\end{array}$ & $\begin{array}{l}20 \\
10\end{array}$ \\
\hline 11 & $\#$ & & & & & & & & & $\#$ & & & & & \\
\hline 12 & $\#$ & & $\#$ & & & & & & $\#$ & $\#$ & & 90 & $\begin{array}{l}50.8 \\
\end{array}$ & 5.08 & 10 \\
\hline 13 & $\#$ & & $\#$ & $\#$ & $\#$ & & $\#$ & & & & $* 2$ & 90 & $\begin{array}{l}106.68 \\
106.68\end{array}$ & $\begin{array}{l}5.59 \\
6.35\end{array}$ & $\begin{array}{l}19 \\
17\end{array}$ \\
\hline 14 & $\#$ & & $\#$ & & $\#$ & & $\#$ & & & & & 90 & 106.93 & 5.59 & 19 \\
\hline 15 & $\#$ & & & \# & & & & & & & & & & & \\
\hline 16 & $\#$ & & \# & $\#$ & $\#$ & & $\#$ & & $\#$ & $\#$ & & & view pap & & \\
\hline 17 & $\#$ & & $\#$ & $\#$ & & & & & & $\#$ & & $\begin{array}{l}90 \\
(90,127,143,160, \\
172)\end{array}$ & $\begin{array}{l}1587.5 \\
1270\end{array}$ & \begin{tabular}{|r|}
12.7 \\
\\
50.8
\end{tabular} & $\begin{array}{l}125 \\
25\end{array}$ \\
\hline 18 & $\#$ & & & $\#$ & & & & & & & & & & & \\
\hline 19 & \# & & & & & & & & & $\#$ & & & & & \\
\hline 20 & $\#$ & & & & & & & & $\#$ & & & 90 & 104.14 & 5.08 & 20.5 \\
\hline 77 & $\#$ & & \# & $\#$ & $\#$ & \# & & & $\#$ & \# & $* 3$ & & view pap & & \\
\hline 21 & $\#$ & & $\#$ & & & & & & & & & $(90,120,135)$ & $\begin{array}{l}82.55 \\
55.63\end{array}$ & \begin{tabular}{|l|}
3.56 \\
3.30
\end{tabular} & $\begin{array}{l}23.5 \\
17.5\end{array}$ \\
\hline 22 & $\#$ & & $\#$ & $\#$ & & & & & & & & $\begin{array}{l}90 \\
(90,127,143,160, \\
172)\end{array}$ & $\begin{array}{l}1587.5 \\
1270\end{array}$ & 12.7 & $\begin{array}{l}125 \\
25\end{array}$ \\
\hline 23 & $\#$ & & $\#$ & $\#$ & $\#$ & & & & $\#$ & $\#$ & & & view pap & & \\
\hline 24 & $\#$ & & & & & & & & & $\#$ & & & & & \\
\hline 25 & $\#$ & & & & & & & & & $\#$ & & & & & \\
\hline 26 & $\#$ & \# & $\#$ & & & & & & $\#$ & & & $\begin{array}{l}90 \\
120\end{array}$ & $\begin{array}{l}82.55 \\
55.63\end{array}$ & $\begin{array}{l}3.56 \\
3.30\end{array}$ & $\begin{array}{l}23.5 \\
17.5\end{array}$ \\
\hline 27 & $\#$ & \# & & & & & & & $\#$ & & & 157.5 & 686 & 11.1 & 61.8 \\
\hline 28 & $\#$ & & $\#$ & $\#$ & $\#$ & & & & $\#$ & $\#$ & & Review paper & & & \\
\hline 29 & & \# & & & & & & & $\#$ & & & 170 & $?$ & $?$ & $?$ \\
\hline 72 & $\#$ & & & & & & & & $\#$ & & *12 & 135 & 452.25 & 9.5 & 47.6 \\
\hline 30 & $\#$ & & & & & & & & & $\#$ & & & & & \\
\hline 31 & $\#$ & & & & & & & & & $\#$ & & & view pap & & \\
\hline 32 & $\#$ & & & $\#$ & & & & & & $\#$ & & & & & \\
\hline 33 & $\#$ & & \# & $\#$ & & & & & & & & 90 & 106.93 & 5.59 & 19 \\
\hline 78 & $\#$ & & & & & & & & & $\#$ & $* 6$ & $\begin{array}{l}(90,105,120,135, \\
150,157.5,168.75)\end{array}$ & & & $\begin{array}{l}10 \\
20 \\
40 \\
60 \\
\end{array}$ \\
\hline 34 & $\#$ & & $\#$ & & & & & & & & *10 & 90 & $\begin{array}{l}23.75 \\
23.25 \\
22.5\end{array}$ & $\begin{array}{l}2.49 \\
3.76 \\
5.00\end{array}$ & $\begin{array}{l}9.5 \\
6.2 \\
4.5\end{array}$ \\
\hline
\end{tabular}




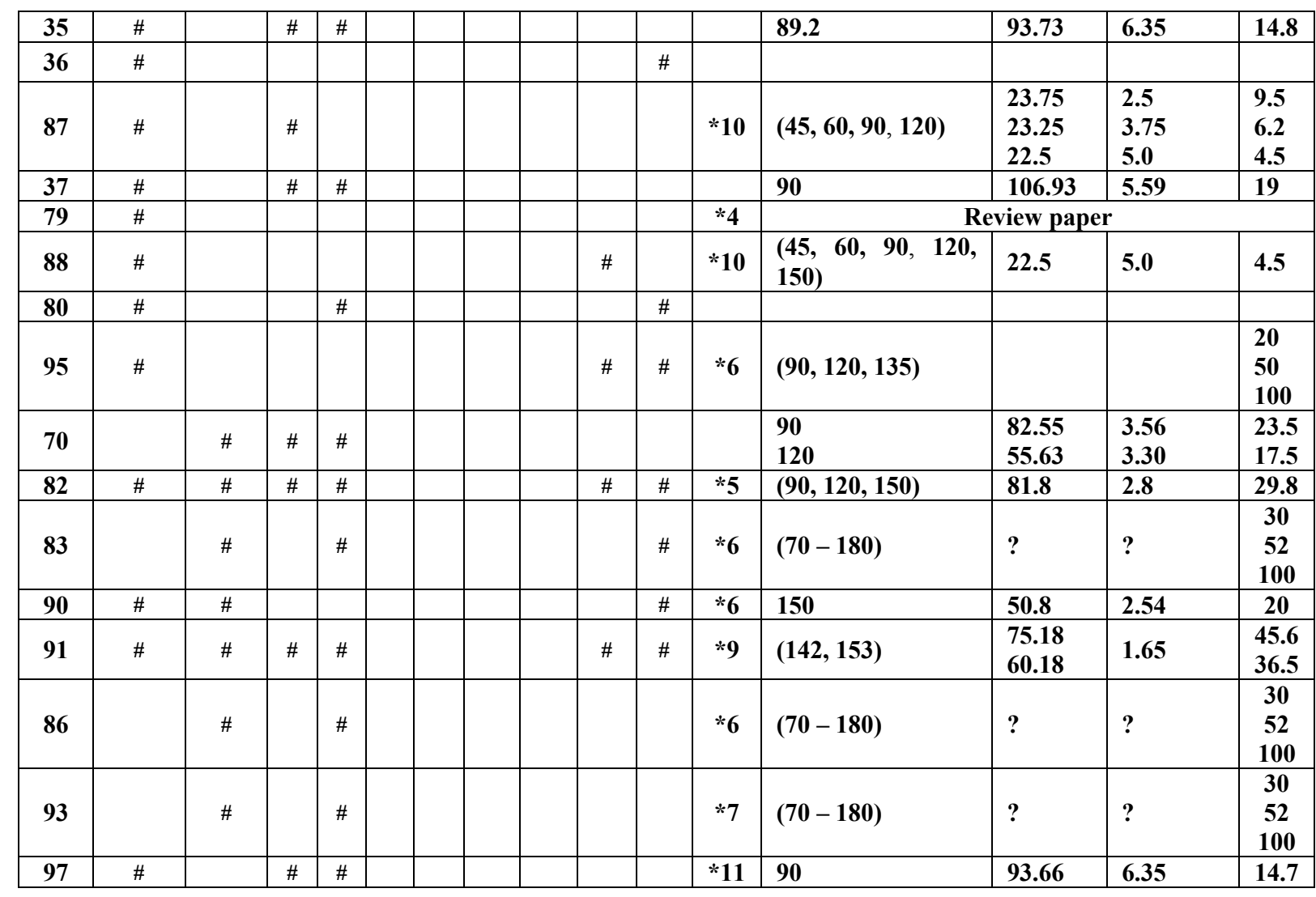

*1 A Bend Angle of 180 degrees is a straight pipe.

*2 Effects of transverse loads considered.

*3 Although text published in 1970, latest mitre reference is 1966 . *4 Reviews work on effects of combined pressure loading, fatigue, minimum distance between cuts and effect of attachments. $\quad * 590^{0}$ specimen used for pressure test had thickness reduced to $1.59 \mathrm{~mm}$ on both inner and outer surfaces, approximately one diameter either side of mitre. $\quad * 6$ These dimensions are for analytical models. $\quad * 7$ Also compares FEA (finite element analysis) with experimental results [70] for $90^{\circ}$ bend. *8 Photo-elastic, frozen stress, Araldite. *9 Reviews some previous work, including standards. *10 Photo-elastic, frozen stress, Araldite. Provides through-thickness results at intersection. *11 Considers hot-spot stresses for fatigue assessment. *12 Considers weld misalignment and low cycle fatigue cracking in an in-service pipeline.

Table 1 Chronological presentation of single un-reinforced mitred bend reference details. 


\begin{tabular}{|c|c|c|c|c|c|c|c|c|c|c|c|c|c|c|c|}
\hline \multirow{3}{*}{ 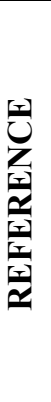 } & \multirow{2}{*}{\multicolumn{2}{|c|}{ NATURE }} & \multicolumn{9}{|c|}{ LOADING } & \multicolumn{4}{|c|}{$\begin{array}{c}\text { EXPERIMENTAL } \\
\text { SPECIMEN DETAILS }\end{array}$} \\
\hline & & & \multicolumn{2}{|c|}{ IPB } & \multicolumn{2}{|c|}{ OPB } & \multicolumn{2}{|c|}{ TORS } & \multicolumn{2}{|c|}{ PRESS } & \multirow[b]{2}{*}{ 졸 } & $\begin{array}{c}\text { BEND } \\
\text { ANGLE }\end{array}$ & \multirow{2}{*}{$\begin{array}{c}\begin{array}{c}\text { Mean } \\
\text { pipe } \\
\text { radius }\end{array} \\
\mathbf{a} \\
(\mathrm{mm})\end{array}$} & \multirow{2}{*}{$\begin{array}{c}\text { Pipe wall } \\
\text { Thickness } \\
\text { t } \\
(\mathrm{mm})\end{array}$} & \multirow[b]{2}{*}{$\mathbf{a} / \mathbf{t}$} \\
\hline & 兽 & 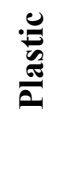 & 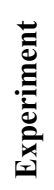 & 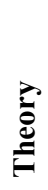 & 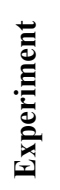 & 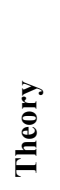 & & 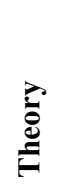 & & 总 & & $\begin{array}{c}\text { (degrees) } \\
* 1\end{array}$ & & & \\
\hline 38 & \# & & & & & & & & & $\#$ & & & & & \\
\hline 39 & $\#$ & & & & & & & & & $\#$ & & & & & \\
\hline 40 & $\#$ & & & & & & & & $\#$ & & & 90 & 1001 & 35 & 28.7 \\
\hline 41 & $\#$ & & & $\#$ & & $\#$ & & $\#$ & & $\#$ & & & & & \\
\hline 2 & \# & & & & & & & & & \# & & & & & \\
\hline 4 & $\#$ & & \# & & & & & & $\#$ & & & 90 & $\begin{array}{l}37.34 \\
116.59\end{array}$ & $\begin{array}{l}1.52 \\
4.83\end{array}$ & $\begin{array}{l}24.5 \\
24.5\end{array}$ \\
\hline 5 & $\#$ & & & & & & & & $\#$ & $\#$ & & 90 & 1016 & 35 & 29 \\
\hline 42 & $\#$ & $\#$ & & & & & & & $\#$ & & & 90 & 1000 & 22.35 & 45 \\
\hline 8 & \# & & $\#$ & $\#$ & & & & & $\#$ & $\#$ & & 90 & 50.8 & 5.08 & 10 \\
\hline 10 & $\#$ & & & & & & & & & $\#$ & & & & & \\
\hline 12 & $\#$ & & $\#$ & $\#$ & & & & & $\#$ & $\#$ & & 90 & $\begin{array}{l}50.8 \\
\end{array}$ & 5.08 & 10 \\
\hline 43 & $\#$ & $\#$ & & & & & & & $\#$ & & & 90 & 1000 & 22.35 & 45 \\
\hline 44 & $\#$ & & $\#$ & $\#$ & $\#$ & $\#$ & $\#$ & $\#$ & $\#$ & $\#$ & $* 2$ & 90 & 76.2 & 5.08 & 15 \\
\hline 16 & $\#$ & $\#$ & $\#$ & $\#$ & $\#$ & $\#$ & $\#$ & $\#$ & $\#$ & $\#$ & & & Review I & aper & \\
\hline 17 & $\#$ & & $\#$ & $\#$ & & & & & & & & 90 & 1270 & 50.8 & 25 \\
\hline 20 & $\#$ & & & & & & & & $\#$ & $\#$ & & $(90,120,150)$ & 104.14 & 5.08 & 20.5 \\
\hline 22 & $\#$ & & $\#$ & $\#$ & & & & & & & & 90 & 1270 & 50.8 & 25 \\
\hline 45 & $\#$ & & & & & & & & $\#$ & & $* 3$ & 90 & 50.8 & 5.08 & 10 \\
\hline 46 & $\#$ & $\#$ & & & & & & & $\#$ & $\#$ & & 90 & 247.90 & $\begin{array}{l}9.65 \\
5.59\end{array}$ & $\begin{array}{l}25 \\
43\end{array}$ \\
\hline 47 & $\#$ & & & & & & & & & $\#$ & & & & & \\
\hline 34 & $\#$ & & $\#$ & & & & & & & & & 90 & $\begin{array}{l}23.75 \\
23.11 \\
25.04\end{array}$ & $\begin{array}{l}2.49 \\
3.76 \\
5.00\end{array}$ & $\begin{array}{l}9.5 \\
6.2 \\
5.0\end{array}$ \\
\hline 35 & $\#$ & & $\#$ & $\#$ & $\#$ & $\#$ & $\#$ & $\#$ & $\#$ & $\#$ & & 90 & 76.2 & 5.08 & 15 \\
\hline 37 & \# & & \# & $\#$ & & & & & & & & 90 & 76.2 & 5.08 & 15 \\
\hline 95 & $\#$ & & & & & & & & $\#$ & $\#$ & $* 5$ & 90 & 360 & 4 & 90 \\
\hline 81 & $\#$ & $\#$ & & & & & & & $\#$ & $\#$ & $* 4$ & 90 & & & $\begin{array}{l}26.2- \\
59\end{array}$ \\
\hline
\end{tabular}

*1 A Bend Angle of 180 degrees is a straight pipe. *2 In-Plane, Out-of-Plane and Axial forces considered. *3 Four different forms of reinforcement considered. $\quad * 4$ Elliptical inserts; Fracture mechanics assessment with pre-machined defects. $\quad * 5$ Elliptical insert; local thickening; Araldite.

Table 2 Chronological presentation of single reinforced mitre bend reference details. 


\begin{tabular}{|c|c|c|c|c|c|c|c|c|c|c|c|c|c|c|c|c|c|c|}
\hline \multirow{3}{*}{ 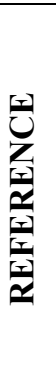 } & \multirow{2}{*}{\multicolumn{2}{|c|}{$\begin{array}{l}\text { NATU } \\
\text { RE }\end{array}$}} & \multicolumn{9}{|c|}{ LOADING } & \multicolumn{7}{|c|}{$\begin{array}{c}\text { EXPERIMENTAL } \\
\text { SPECIMEN DETAILS }\end{array}$} \\
\hline & & & \multicolumn{2}{|c|}{ IPB } & \multicolumn{2}{|c|}{ OPB } & \multicolumn{2}{|c|}{ TORS } & \multicolumn{2}{|c|}{ PRESS } & \multirow[b]{2}{*}{ 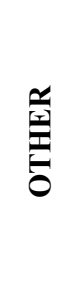 } & \multirow{2}{*}{ 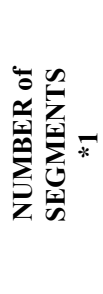 } & \multirow{2}{*}{ 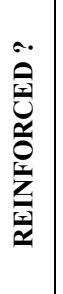 } & $\begin{array}{c}\text { BEND } \\
\text { ANGLE }\end{array}$ & \multirow{2}{*}{$\begin{array}{c}\text { BEND } \\
\text { RADIUS }\end{array}$} & \multirow{2}{*}{$\begin{array}{c}\begin{array}{c}\text { Mean } \\
\text { pipe } \\
\text { radius }\end{array} \\
\mathbf{a} \\
(\mathrm{mm})\end{array}$} & \multirow{2}{*}{$\begin{array}{c}\text { Pipe wall } \\
\text { thickness } \\
\mathbf{t} \\
(\mathrm{mm})\end{array}$} & \multirow[b]{2}{*}{$\mathbf{a} / \mathbf{t}$} \\
\hline & 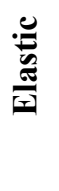 & 产 & 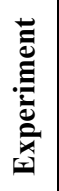 & 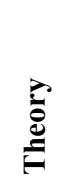 & 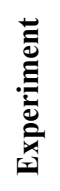 & : & 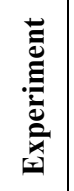 & 莺 & 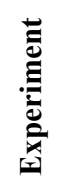 & : & & & & $\begin{array}{c}\text { (degrees) } \\
* \mathbf{2}\end{array}$ & & & & \\
\hline 48 & $\#$ & & $\#$ & & $\#$ & & & & & & & 1 & $\mathbf{N}$ & 90 & 195.3 & 54.1 & 6.1 & 9 \\
\hline 38 & $\#$ & & & & & & & & & & & & $\mathrm{~N}$ & & & & & \\
\hline 49 & \# & & $\#$ & & & & & & & & & 4 & $\mathbf{N}$ & 90 & 181.0 & 130.9 & 1.4 & 93.5 \\
\hline 50 & $\#$ & \# & $\#$ & & & & & & & & & 5 & $\mathrm{~N}$ & 90 & 339.7 & 152.4 & 3.18 & 48 \\
\hline 1 & \# & & \# & & \# & & & & & & & $(1,2,5)$ & $\mathrm{N}$ & 90 & 195.3 & 54.1 & 6.1 & 9 \\
\hline 51 & \# & & \# & & & & & & & & & 5 & $\mathrm{~N}$ & 90 & 339.7 & 152.4 & 3.18 & 48 \\
\hline 52 & \# & $\#$ & \# & $\#$ & \# & & & & $\#$ & & & 2 & $\mathbf{N}$ & 90 & 457.2 & 157.2 & 9.53 & 16.5 \\
\hline 53 & $\#$ & $\#$ & $\#$ & & & & & & $\#$ & & & 1 & $\mathbf{N}$ & 90 & 457.2 & 157.2 & 9.53 & 16.5 \\
\hline 2 & $\#$ & & & & & & & & & $\#$ & & & $\mathbf{N}$ & & & & & \\
\hline 54 & \# & \# & \# & & \# & & \# & & \# & & & $(1,2)$ & $\mathbf{N}$ & 90 & 457.2 & 157.2 & 9.53 & 16.5 \\
\hline 55 & $\#$ & & \# & & $\#$ & & & & \# & & & $\begin{array}{l}1 \\
1 \\
2\end{array}$ & $\mathbf{N}$ & 90 & $\begin{array}{l}139.7 \\
228.6 \\
304.8\end{array}$ & 81.1 & 7.06 & 11.5 \\
\hline 12 & $\#$ & & $\#$ & $\#$ & $\#$ & & & & $\#$ & $\#$ & & 3 & $\mathbf{N}$ & 90 & 2573.1 & 1010.4 & 39.69 & 25.5 \\
\hline 56 & $\#$ & & \# & \# & & & & & & & & $\begin{array}{l}1 \\
3\end{array}$ & $\mathbf{N}$ & 360 & $\begin{array}{l}228.6 \\
508\end{array}$ & $\begin{array}{l}76.2 \\
156.4\end{array}$ & $\begin{array}{l}1.22 \\
5.0\end{array}$ & $\begin{array}{l}62.5 \\
31.3\end{array}$ \\
\hline 57 & $\#$ & & $\#$ & $\#$ & & & & & & & & $\begin{array}{l}1 \\
3\end{array}$ & $\mathbf{N}$ & 360 & $\begin{array}{l}228.6 \\
508\end{array}$ & $\begin{array}{l}76.2 \\
156.4\end{array}$ & $\begin{array}{l}1.22 \\
5.0\end{array}$ & $\begin{array}{l}62.5 \\
31.3\end{array}$ \\
\hline 58 & $\#$ & & $\#$ & $\#$ & & & & & & & & $\begin{array}{l}1 \\
3\end{array}$ & $\mathbf{N}$ & 360 & $\begin{array}{l}228.6 \\
508\end{array}$ & $\begin{array}{l}76.2 \\
156.4\end{array}$ & $\begin{array}{l}1.22 \\
5.0\end{array}$ & $\begin{array}{l}62.5 \\
31.3\end{array}$ \\
\hline 16 & \# & & \# & $\#$ & \# & & $\#$ & & $\#$ & & & & & & Review p & per & & \\
\hline 17 & \# & & & $\#$ & & & & & & & & & $\mathrm{~N}$ & & & & & \\
\hline 18 & \# & & $\#$ & $\#$ & & & & & & & & 3 & $\mathbf{N}$ & 360 & 508 & 156.4 & 5.0 & 31.3 \\
\hline 59 & $\#$ & & \# & \# & & & & & & & & $\begin{array}{c}5 \\
(1,2) \\
3 \\
\end{array}$ & $\mathrm{~N}$ & $\begin{array}{c}90 \\
90 \\
360 \\
\end{array}$ & $\begin{array}{l}339.7 \\
457.2 \\
508 \\
\end{array}$ & $\begin{array}{l}152.4 \\
157.2 \\
156.4\end{array}$ & $\begin{array}{l}3.18 \\
9.53 \\
5.0\end{array}$ & $\begin{array}{l}48 \\
16.5 \\
31.3\end{array}$ \\
\hline 77 & $\#$ & $\#$ & $\#$ & $\#$ & & & & & $\#$ & & $* 3$ & & & & Review p & per & & \\
\hline 22 & $\#$ & & & $\#$ & & & & & & & & & $\mathbf{N}$ & & & & & \\
\hline 60 & $\#$ & & $\#$ & $\#$ & & & & & & & & 2 & $\mathbf{N}$ & 90 & 1143 & 381 & 3.12 & 122 \\
\hline 23 & $\#$ & & $\#$ & $\#$ & $\#$ & & & & \# & & & & & & Review p & per & & \\
\hline 24 & $\#$ & & & & & & & & $\#$ & \# & & $(1,2)$ & $\mathbf{N}$ & 90 & 457.2 & 157.2 & 9.53 & 16.5 \\
\hline 25 & $\#$ & $\#$ & $\#$ & $\#$ & $\#$ & $\#$ & & & $\#$ & $\#$ & & 2 & $\mathrm{~N}$ & 90 & $\begin{array}{l}1143 \\
1371.6 \\
914.4\end{array}$ & $\begin{array}{l}381 \\
457.2 \\
304.8\end{array}$ & $\begin{array}{l}3.12 \\
3.3 \\
3.25\end{array}$ & $\begin{array}{l}122 \\
138.5 \\
93.75\end{array}$ \\
\hline 61 & $\#$ & & & & $\#$ & $\#$ & & & & & & 2 & $\mathbf{N}$ & 90 & 1143 & 381 & 3.12 & 122 \\
\hline 62 & $\#$ & & $\#$ & & $\#$ & & & & \# & $\#$ & & 2 & $\mathbf{N}$ & 90 & 1371.6 & 457.2 & 3.3 & 138.5 \\
\hline 63 & $\#$ & & $\#$ & & & & & & $\#$ & $\#$ & & 2 & $\mathrm{~N}$ & 90 & 914.4 & 304.8 & 3.25 & 93.75 \\
\hline 64 & $\#$ & & $\#$ & $\#$ & & & & & & & & 2 & $\mathbf{N}$ & 90 & 457.2 & 157.2 & 9.53 & 16.5 \\
\hline 28 & $\#$ & & $\#$ & $\#$ & $\#$ & $\#$ & & & $\#$ & $\#$ & & & & & Review p & per & & \\
\hline 74 & $\#$ & & & & & & & & & & $* 14$ & 1 & $\mathbf{N}$ & 90 & 1400 & 924 & 48.5 & 19 \\
\hline 65 & $\#$ & & & $\#$ & & \# & & \# & & \# & & 2 & $\mathrm{~N}$ & 90 & 1219.2 & 654.1 & 63.5 & 10.3 \\
\hline 66 & $\#$ & & \# & & & & & & $\#$ & & & 1 & ${ }^{* 4}$ & 90 & 500 & 501 & 9.4 & 53 \\
\hline 30 & $\#$ & & & $\#$ & & $\#$ & & & & $\#$ & & & $\mathrm{~N}$ & & & & & \\
\hline 31 & $\#$ & & & $\#$ & & \# & & & & $\#$ & & & & & Review p & per & & \\
\hline
\end{tabular}




\begin{tabular}{|c|c|c|c|c|c|c|c|c|c|c|c|c|c|c|c|c|}
\hline 96 & $\#$ & \# & & & & & & $\#$ & $* 13$ & $\begin{array}{l}\mathbf{3} \\
\mathbf{2} \\
\mathbf{1} \\
\mathbf{3} \\
\mathbf{3} \\
\mathbf{3} \\
\mathbf{3}\end{array}$ & $\mathbf{N}$ & 90 & $\begin{array}{l}1102 \\
846 \\
551 \\
1102 \\
558 \\
1706 \\
1268 \\
\end{array}$ & $\begin{array}{l}228.5 \\
228.5 \\
228.5 \\
228.5 \\
228.5 \\
228.5 \\
255.5\end{array}$ & $\begin{array}{l}8.2 \\
8.2 \\
8.2 \\
8.2 \\
8.2 \\
8.2 \\
8.7 \\
\end{array}$ & $\begin{array}{l}27.9 \\
27.9 \\
27.9 \\
27.9 \\
27.9 \\
27.9 \\
29.4\end{array}$ \\
\hline 67 & \# & & & & & & & & $* 5$ & & $\mathbf{N}$ & & & & & \\
\hline 68 & \# & & & & & & & & $* 6$ & & $\mathbf{N}$ & & & & & \\
\hline 78 & \# & \# & & & & & \# & \# & $* 11$ & 3 & $\mathbf{N}$ & 90 & 973 & 499 & 8.5 & 58.6 \\
\hline 69 & $\#$ & & \# & \# & \# & \# & \# & $\#$ & $* 7$ & $\begin{array}{l}3 \\
5\end{array}$ & $\mathbf{N}$ & 360 & $\begin{array}{l}609.6 \\
827.6 \\
\end{array}$ & 150.4 & 4.1 & 36 \\
\hline 36 & $\#$ & & & \# & & & & \# & $* 8$ & 1 & $\mathbf{N}$ & 120 & $\begin{array}{l}2436.6 \\
2459.6\end{array}$ & $\begin{array}{l}768.4 \\
771.5 \\
\end{array}$ & $\begin{array}{l}25.4 \\
19.1 \\
\end{array}$ & $\begin{array}{l}30.3 \\
40.4 \\
\end{array}$ \\
\hline 71 & \# & & & $\#$ & & \# & & & $* 9$ & & $\mathbf{N}$ & & & & & \\
\hline 79 & \# & & & & & & & & $* 10$ & & $\mathbf{N}$ & \multicolumn{5}{|c|}{ Review paper } \\
\hline 84 & $\#$ & $\#$ & $\#$ & $\#$ & $\#$ & \# & $\#$ & $\#$ & $* 4$ & 3 & $\mathbf{N}$ & 90 & 250 & 126.7 & 9.87 & 12.8 \\
\hline 95 & $\#$ & & & & & & $\#$ & $\#$ & $* 12$ & 1 & $\mathbf{N}$ & 90 & 470 & 360 & 4 & 90 \\
\hline 89 & & \# & & $\#$ & & & & & $* 8$ & 2 & $\mathbf{N}$ & 90 & 1650 & 546 & $\begin{array}{l}43.68 \\
21.84 \\
10.92 \\
\end{array}$ & $\begin{array}{l}12.5 \\
25 \\
50 \\
\end{array}$ \\
\hline 83 & $\#$ & \# & \# & \# & & & \# & \# & $* 4$ & 3 & $\mathbf{N}$ & 90 & 250 & 124.8 & 5.9 & 21.1 \\
\hline 85 & $\#$ & \# & $\#$ & $\#$ & $\#$ & $\#$ & $\#$ & $\#$ & $* 4$ & 3 & $\mathbf{N}$ & 90 & 250 & 126.7 & 9.87 & 12.8 \\
\hline 94 & & $\#$ & $\#$ & $\#$ & & & $\#$ & $\#$ & $* 4$ & 3 & $\mathbf{N}$ & 90 & 250 & 124.8 & 5.9 & 21.1 \\
\hline
\end{tabular}

*1 A single mitre has zero segments.

*2 A Bend Angle of 180 degrees is a straight pipe.

*3 Although text published in 1970, latest mitre reference is 1966. *4 GRP bends with PVC liners; Average dimensions tabulated; Thickness is for GRP + liner. *5 In Japanese - provides basis for [71]. $\quad$ *6 In Japanese. *7 Dimensions tabulated calculated assuming pipe used is same for both bends. $\quad * 8$ These dimensions are for analytical models. $\quad$ *9 Presents a 'new' ring finite element and compares results with [58] for IPB.

*10 Reviews work on effects of combined pressure loading, fatigue, minimum distance between cuts and effect of attachments. $\quad * 11$ Also compares elastic and plastic shell FEA results with $[\mathbf{5}, \mathbf{1 0}, \mathbf{2 7}, \mathbf{5 4 , 6 3 , 9 6 ] .}$

*12 Araldite *13 Bends tested to burst. Two bends tested in fatigue before bursting statically. Two different types of steel used. $\quad * 14$ Vibration induced stresses considered. Approximate bend sizes listed.

Table 3 Chronological presentation of multi-mitre / lobster-back / gusseted bend reference details. 


\section{List of Figure and Table Titles}

Figure 1. Mitred Pipe Bend 'Spectrum'

Figure 2. Types of Reinforcement

Figure 3. Mitre Pipe Bend Publications

Figure 4. Typical Experimental Loading Arrangements

Figure 5. Unit Load Case Possibilities

Table 1 Chronological presentation of single un-reinforced mitred bend reference details.

Table 2 Chronological presentation of single reinforced mitre bend reference details.

Table 3 Chronological presentation of multi-mitre / lobster-back / gusseted bend reference details. 